\title{
FLUJOS TURÍSTICOS, CAPITAL TERRITORIAL Y USO DE LA BICICLETA. ANDALUCÍA COMO MODELO DE DESTINO EMERGENTE EN CICLOTURISMO
}

\section{TOURISM FLOWS, TERRITORIAL CAPITAL AND CYCLING. ANDALUSIA AS A MODEL OF EMERGING CYCLE TOURISM DESTINATION}

\author{
Francisco M. Fernández-Latorre \\ Universidad de Sevilla \\ flatorre@us.es
}

Recibido: noviembre, 2014.

Versión final aceptada: febrero, 2015.

PALABRAS CLAVE: Flujos turísticos, capital territorial, cicloturismo, transporte sostenible, infraestructuras verdes.

KEY WORDS: Tourism flows, territorial capital, cycling, sustainable transport, green infraestructures.

\section{RESUMEN}

El artículo pretende analizar las relaciones entre capital territorial y cicloturismo, y especialmente, las conexiones de los flujos turísticos con factores básicos de capital territorial como la longitud de costa, los bienes de interés cultural, los espacios naturales protegidos y la población; y sus implicaciones para el desarrollo del cicloturismo.

A tal fin se realiza un análisis de correlación lineal de estas variables en las comunidades autónomas españolas. Por otro lado, identifica las condiciones particulares del capital terrritorial de Andalucía para el desarrollo del cicloturismo mediante diversos indicadores, así como de los instrumentos sectoriales de planificación existentes, junto a las principales tendencias globales del mercado.

La estructura del mercado potencial del cicloturismo se analiza contrastando el perfil del turista que visita Andalucía, según el grado de utilización de la bicicleta en su país o comunidad de origen, y los flujos turísticos que genera. Finalmente, se propone un modelo multidimensional de cicloturismo basado en la óptica de capital territorial, estableciendo unas conclusiones y recomendaciones para la evaluación, planificación y gestión integrada del sector. 

cicloturismo.

\section{ABSTRACT}

The article analyzes the relationships between territorial capital and cycle tourism, and more specifically, the interconnections that exist between tourism flows, coastline length, assets of cultural interest, protected natural areas and population; as well as their influence on cycle tourism.

To this end, a linear correlation analysis was conducted amongst Spanish Autonomous Communities. Furthermore, particular conditions of territorial capitals were identified by using a number of indicators, as well as existing sectorial planning instruments and global market trends.

A potential market structure is outlined by contrasting tourist profiles according to the percentage of total number of journeys by bicycle in the tourist source community and generated tourism flows. Finally, a multidimensional model for cycle tourism is proposed, a set of conclusions and recommendations for assessment, planning and integrated management of the sector are defined. 


\section{INTRODUCCIÓN.}

El uso de la bicicleta como medio de transporte y, más aun, como recurso turístico, ha sido tradicionalmente, de carácter marginal. A nivel mundial en 1997 existían 297 empresas que ofertaban servicios de cicloturismo en diferentes países según el Specialty Travel Index (Ritchie, W. B., 1998), lideradas por Gran Bretaña (27), Francia (21) y Canadá (19). España contaba ese año con nueve empresas, aproximadamente un $3 \%$ del total mundial.

A pesar de existir una demanda creciente de productos cicloturísticos, las investigaciones que tratan las interacciones entre el fenómeno turístico y la bicicleta continúan siendo escasas, y marcadas por la disparidad de criterios en la definición del cicloturismo (Lamont, M., 2009). En 1998 Ritchie aborda la problematica de definir la actividad cicloturística, y basandose en los trabajos de Simonsen y Jorgenson, (1996), la representa como un continuum entre dos polos diferenciados; conformado por los ciclistas entusiastas en un extremo, y los ciclistas de frecuencia ocasional, en el otro. El cicloturismo viene definido por aquellas visitas recreativas, con o sin pernoctaciones, de al menos un día fuera de casa, en las que la actividad recreativa ciclista es parte fundamental y significativa (Sustrans, 1999). Cabe diferenciar tres tipos de cicloturismo: vacaciones ciclistas, centradas en el ciclismo (cycling holidays), ciclismo en vacaciones, donde la actividad ciclista es una actividad más entre las desarrolladas en las vacaciones (holiday cycling), y excursiones ciclistas de un día, consistentes habitualmente en excursiones de un día o medio día (cycling day visit), según la distinción de Sustrans (1999). El cicloturismo puede encuadrase conceptualmente dentro del denominado turismo de cruceros, en el que el propio medio de transporte constituye una experiencia o atractivo turístico, y en cierto modo, comparte características con el turismo de peregrinación, aunque se suele clasificar en la categoría de turismo deportivo.

Por otro lado, las exigencias para desarrollar modelos de turismo hipocarbónicos son cada vez más acuciantes, a causa de la problemática del cambio climático. La importancia de la Huella Ecológica Energética en destinos turísticos es muy elevada; supone más del $50 \%$ de la Huella Ecológica de Canarias (Fernández Latorre, F. M. y Díaz del Olmo, F. ,2011b,c). Además, la demanda creciente de electricidad puede generar conflictos en la capacidad de carga de las infraestructuras energéticas del destino, con repercusiones sobre la sostenibilidad turística y la población local (Fernández Latorre, F. M., 2011a). Bajo estos condicionantes, el cicloturismo se considera un modelo turístico a potenciar, en la medida que contribuye a reducir la huella ecológica y promueve el contacto directo con las comunidades locales y el patrimonio natural y cultural.

Si bien se reconoce que el cicloturismo depende en gran medida de una buena combinación de las infraestructuras turísticas con los recursos atractivos básicos (Meschik, M., 2012), los estudios que relacionan la dotación de recursos naturales y 
culturales con el cicloturismo son exiguos, y prácticamente inexistentes si se abordan desde la óptica más amplia del capital territorial. De ahí que la mayoria de los modelos desarrollados en torno al cicloturismo se centren en aspectos sectoriales, como el sistema de transporte (Lumsdon, L., 2000), el impacto medioambiental o climático (Zia Wadud (2014, Brandenburg,C., 2007), el impacto económico (Zovko, I., 2013), y sobre la salud (Wang, G., et al., 2005).

El «capital territorial» es un concepto que comprende elementos muy diferentes con características sustanciales: estar incorporadas de manera estable a los lugares (inmóviles), no hallarse fácilmente en otro lugar con la misma calidad, y no poder ser producidas sin esfuerzo en breve tiempo (Dematteis, G. y Governa, F., 2005). El conjunto de factores que lo componen consta de recursos del medio natural (renovables y no renovables); patrimonio histórico material e inmaterial; capital fijo acumulado en infraestructuras y equipamientos; así como bienes relacionales (Storper, 1997), que abarcan el capital cognitivo local, el capital social, la heterogeneidad cultural y la capacidad institucional. Consecuentemente, el enfoque del capital territorial presenta afinidad con los sistemas de indicadores de sostenibilidad basados en un enfoque socio-económico-ambiental (Fernández-Latorre, F., 2006). Bajo esta óptica, el sistema turístico puede considerarse parte del capital territorial, tanto en sus infraestructuras y equipamientos como en los bienes intangibles asociados al mismo.

Cada región posee una capacidad particular para aprovechar su capital territorial, y requiere por tanto de estrategias específicas (Camagni, R. \& Capello, R., 2013). En esta línea, la Unión Europea promueve el desarrollo espacial policentrico del sistema urbano, y la complementareidad y partenariados urbano-rural (European Commission, 1999), conducente a transformar la diversidad territorial en fortalezas valorizables (Commission of the European Communities, 2006a). Por su parte, la región mediterránea se distingue por un fuerte capital territorial, frecuentemente subexplotado (OTREMED, 2012), ligado, en mayor o menor medida al fenómeno turístico, y éste, a su vez al desarrollo policentrico (Pompili, T., Martinoia,M., 2011). Estos mismo autores encontraron una asociación significativa del capital cultural con el empleo turístico en distintas regiones de Italia.

\section{OBJETIVOS Y METODOLOGÍA.}

El objetivo central del trabajo consiste en estudiar las relaciones entre el capital territorial y el cicloturismo, aplicado al caso de Andalucía. Las principales cuestiones a explorar son las siguientes:

1. ¿Existen condiciones particulares de capital territorial en Andalucía para el desarrollo del cicloturismo? ¿Cuáles?

2. ¿Cómo se correlacionan ? ¿Qué implicaciones supone de cara al cicloturismo?

3. ¿Qué tendencias a nivel internacional y nacional deben tenerse en cuenta para el desarrollo del cicloturismo en una región turística como Andalucía?

ISSN: 0212-8594 ISSN-e: 2340-2776.N№ DOI: http://dx.doi.org/10.12795/rea.2015.i32.04 
Para dar respuesta a los objetivos planteados se parte, en primer lugar, del estudio de las condiciones particulares de Andalucía, tanto de capital natural y cultural, como de capital social. Para ello se emplean diversos indicadores de dotación de capital territorial. El análisis del capital social se centra en los instrumentos de planificación territorial y de la bicicleta con repercusiones directas sobre el cicloturismo.

El contexto general de los macroflujos turísticos en España y Andalucía se aborda mediante análisis de correlación lineal de las pernoctaciones hoteleras con los factores básicos de capital territorial siguientes: longitud de costa, número de bienes de interés cultural, superficie relativa de espacios naturales protegidos y número de habitantes. $\mathrm{A}$ partir de estas correlaciones obtenidas para las comunidades autónomas se esbozan algunas orientaciones para el cicloturismo.

Seguidamente se estudia de forma panorámica el contexto específico del mercado cicloturístico, identificando tendencias y factores clave. La estructura del mercado potencial del cicloturismo en función de su procedencia se analiza a partir del perfil del turista que visita Andalucía y el grado de utilización de la bicicleta en su país o comunidad de origen. Finalmente, se propone un modelo de cicloturismo, estableciendo unas conclusiones y recomendaciones finales.

\section{RESULTADOS.}

\subsection{CONDICIONES PARTICULARES DE CAPITAL TERRITORIAL.}

\subsubsection{CAPITAL NATURAL Y CULTURAL.}

Andalucía posee un capital territorial extraordinario para el desarrollo del cicloturismo gracias a sus condiciones climáticas favorables pero diversas, un vasto y singular patrimonio cultural y natural, y un extenso litoral (cuadro 1). La dotación de Andalucía en espacios naturales protegidos y bienes de interés de interés cultural es la mayor de las comunidades autónomas de España.

A esto se suma que, en torno al $22 \%$ de las vías verdes en España (antiguos trazados ferroviarios recuperados como itinerarios cicloturistas), y más de $1000 \mathrm{~km}$ de ferrocarriles en desuso se localizan en Andalucía (Fundación de Ferrocarriles Españoles y Consejería de Fomento y Vivienda, 2014). Como consecuencia, las vías verdes ofertan una destacada gama de productos cicloturísticos en el territorio andaluz. Muestra de ello son los empleos y servicios vinculados a estos equipamientos, en la Vía Verde de la Sierra -que incluye actividades en el Observatorio de Buitres de Zaframagón-, la Vía Verde de la Sierra Norte de Sevilla, y las Vías Verdes de la Subbética y Vía Verde del Aceite. Existen dos factores muy importantes del capital territorial andaluz que facilitan el crecimiento del cicloturismo, aparte de los descritos, que son la presencia de un sistema turístico muy competitivo y consolidado a nivel internacional, y un

ISSN: 0212-8594 ISSN-e: 2340-2776.№ DOI: http://dx.doi.org/10.12795/rea.2015.i32.04

REA 32 (2015):76-107

http://editorial.us.es/es/revista-de-estudios-andaluces 
Flujos turísticos, capital territorial y uso de la bicicleta. Andalucía como modelo de destino emergente en cicloturismo.

sistema de ciudades policéntrico, que favorece igualmente el enlace entre ciudades, recursos y núcleos turísticos de distinto tamaño y función. Por una parte, las ciudades

Cuadro 1. Dotación de capital natural y cultural de Andalucía.

\begin{tabular}{|c|c|c|c|c|c|}
\hline & $\begin{array}{l}\text { Espacios Naturales Protegidos (ENP) } \\
\text { (ha) (2010) }\end{array}$ & $\begin{array}{l}\text { Vías verdes } \\
(2010)\end{array}$ & $\begin{array}{l}\text { Bienes de Interés } \\
\text { Cultural }\end{array}$ & $\begin{array}{l}\text { Km de } \\
\text { costa }\end{array}$ & $\begin{array}{l}\text { Km de } \\
\text { playa }\end{array}$ \\
\hline Andalucía & $1.699 .829,07$ & 316 & 5.088 & 945 & 562 \\
\hline Aragón & $123.865,64$ & 137 & 787 & 0 & 0 \\
\hline Asturias & $352.168,82$ & 90 & 337 & 401 & 56 \\
\hline Balears (Illes) & $104.712,29$ & 0 & 3.056 & 1.428 & 99 \\
\hline Canarias & $339.126,93$ & 0 & 1.471 & 1.583 & 246 \\
\hline Cantabria & $56.885,13$ & 36 & 283 & 284 & 48 \\
\hline Castilla y León & $650.776,00$ & 90 & 1.373 & 0 & 0 \\
\hline Castilla -La Mancha & $322.058,16$ & 130 & 778 & 0 & 0 \\
\hline Cataluña & $267.448,89$ & 157 & 2.644 & 699 & 325 \\
\hline Comunitat Valenciana & $252.430,61$ & 148 & 1.430 & 518 & 241 \\
\hline Extremadura & $305.595,37$ & 56 & 311 & 0 & 0 \\
\hline Galicia & $396.008,56$ & 6 & 678 & 1.498 & 537 \\
\hline Madrid (Comunidad) & $110.488,73$ & 66 & 1.010 & 0 & 0 \\
\hline Murcia (Región) & $77.832,07$ & 48 & 1.412 & 274 & 92 \\
\hline Navarra & $84.878,14$ & 79 & 2.371 & 0 & 0 \\
\hline País Vasco & $84.308,90$ & 143 & 383 & 246 & 23 \\
\hline Rioja (La) & $24.210,06$ & 70 & 158 & 0 & 0 \\
\hline
\end{tabular}

Fuente: Elaboración propia a partir de Excelltur (2013) y Adeac (2013).

principales andaluzas gozan de una buena conectividad, amplificada por el fenómeno turístico a través de la red de nodos de transporte. Y por otra parte, las ciudades medias andaluzas conforman piezas claves en el tejido patrimonial histórico y cultural, integrando, o actuando de tejido conector de ciudades patrimoniales, conjuntos históricos, bienes de interés cultural y redes patrimoniales, así como de espacios naturales y del litoral (mapas 1 y 2). De modo que el territorio andaluz ejemplifica a la perfección el fenómeno de complementariedad y capacidad de atracción descrito por Giffinger y Suitner (2010) respecto a los sistemas urbanos y la policentricidad como recursos. 
Flujos turísticos, capital territorial y uso de la bicicleta. Andalucía como modelo de destino emergente en cicloturismo.

Mapa 1. Redes de capital cultural.

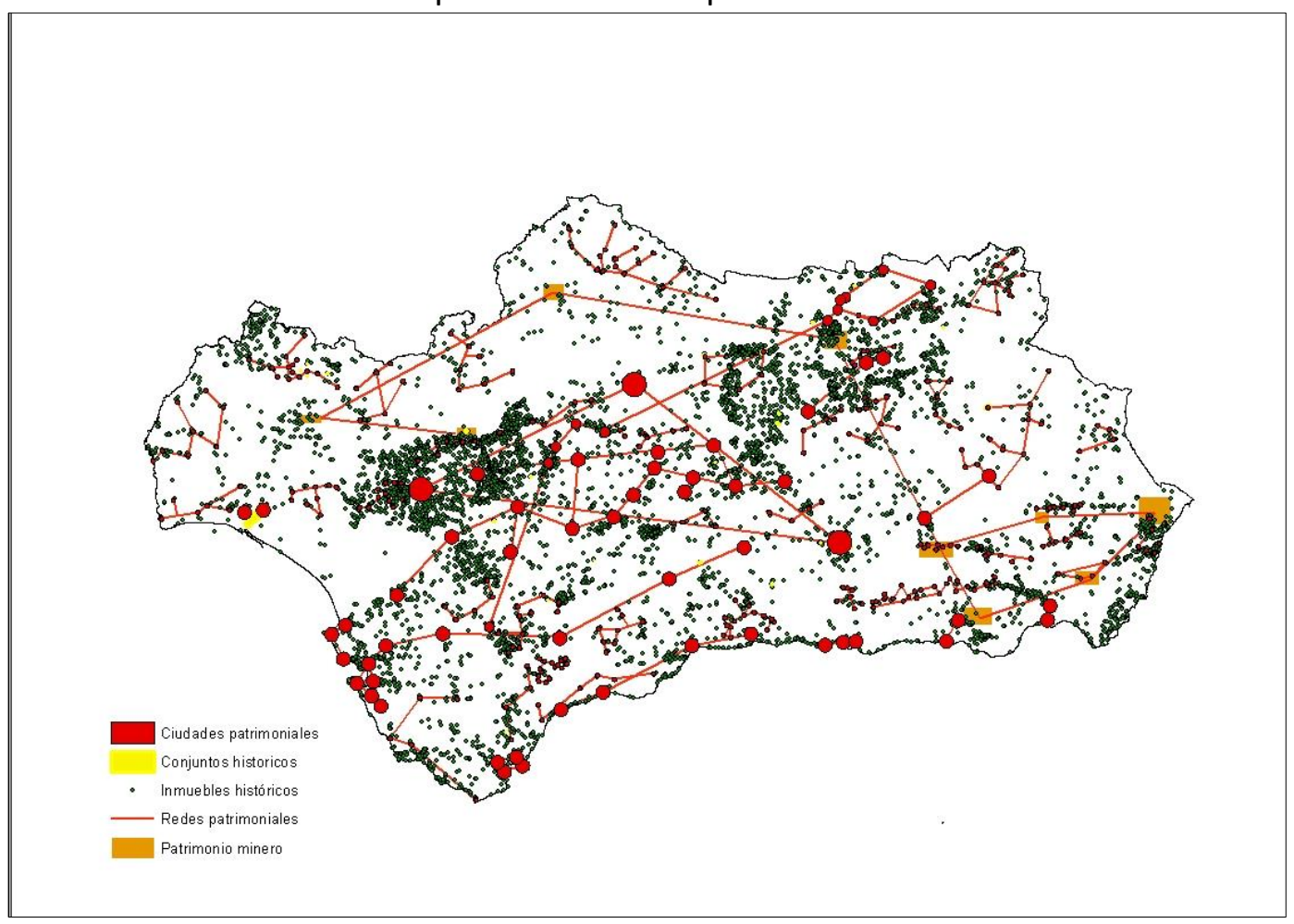

Fuente: Elaboración propia a partir de POTA y REDIAM.

Mapa 2. Redes de capital natural, vías cicloturistas, sistema de ciudades y densidad turística.

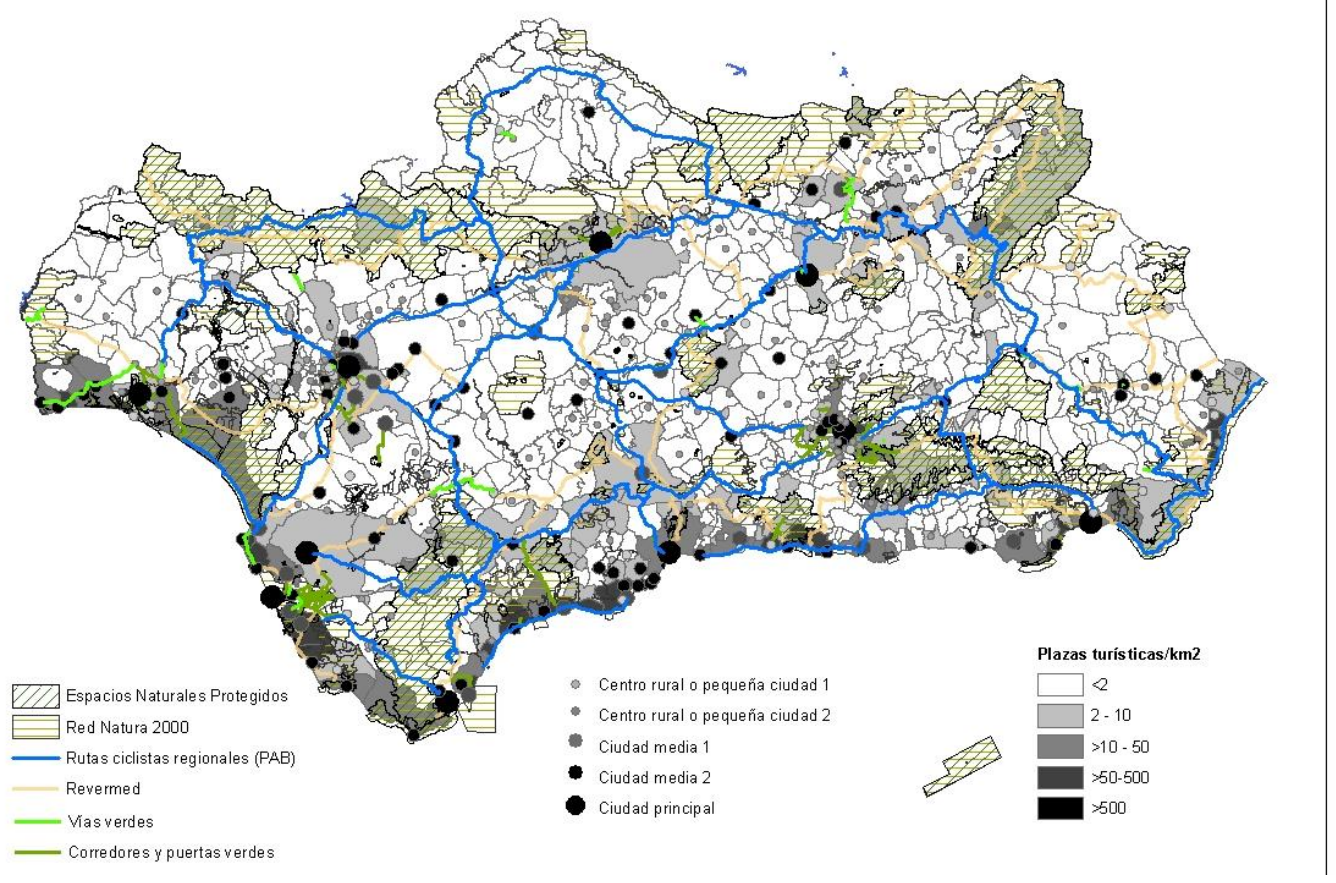

Fuente: Elaboración propia a partir de Rediam, Fundación Vías Verdes, IECA y POTA.

ISSN: 0212-8594 ISSN-e: 2340-2776.No DOI: http://dx.doi.org/10.12795/rea.2015.i32.04

REA 32 (2015):76-107

http://editorial.us.es/es/revista-de-estudios-andaluces 
Complementariamente, la red de vías pecuarias constituye un extenso y valioso patrimonio territorial tanto en la vertiente natural como cultural, formado por más de $25.000 \mathrm{~km}$, y por tanto, un importante recurso para el cicloturismo. De acuerdo con el Plan para la Recuperación y Ordenación de la Red de Vías Pecuarias de Andalucía, se trata de la red de vías pecuarias más extensa de España, lo que la hace especialmente apta para actividades cicloturísticas, y múltiples funciones recreativas, como el senderismo, el turismo ecuestre, y las peregrinaciones. Son además elemento esencial en la ordenación del territorio, y favorecen la diversificación del paisaje, especialmente en los entornos urbanos. Las vías pecuarias suponen una plataforma para el desarrollo rural, al favorecer la fijación de la población en zonas rurales regresivas debido a su alto potencial para el desarrollo de actividades económicas como el turismo de naturaleza, la puesta en valor del patrimonio cultural y la potenciación de productos locales artesanales. Además, la red de vías pecuarias presta funciones de conectividad ecológica, de importancia para la biodiversidad e intercambio genético de especies, como reconoce la ley 42/2007, de 13 de diciembre, del Patrimonio Natural y de la Biodiversidad. En esta línea, la Consejería de Medio Ambiente y Ordenación del Territorio ha definido un sistema de corredores y puertas verdes para todos los municipios andaluces con población superior a los 50.000 habitantes (Consejería de Medio Ambiente y Ordenación del Territorio a, 2014). Suponen itinerarios no motorizados que articulan ámbitos urbanos con el entorno natural más próximo, y con parques periurbanos, metropolitanos y otros puntos de interés.

La diversidad orográfica y altitudinal andaluza multiplica la diversidad climática y paisajística, y posibilita la desestacionalización y complementariedad de destinos y rutas cicloturísticas. Así, en el ámbito del cicloturismo de montaña la Red TransAndalus ofrece un recorrido circular en Andalucía de más de 2.000 kilómetros, (TrasAndalus, 2014), así como Transnevada, ruta que bordea toda Sierra Nevada, con una longitud total de aproximadamente $450 \mathrm{~km}$ (Consejería de Medio Ambiente y Ordenación del Territorio b, 2014). Esta complementariedad se refuerza con las posibilidades de combinación de las rutas cicloturísticas, aparte de su componente de recreación naturalística, con los recursos culturales, tanto de grandes ciudades turísticas patrimoniales como Sevilla, Granada y Córdoba, como de ciudades intermedias, con conjuntos históricos, distribuidos en toda la matriz territorial con bienes de interés cultural profusamente repartidos. Una muestra del potencial de fusión de estos recursos patrimoniales es el producto turístico ofrecido por Andalusian Wilderness, que combina espacios naturales protegidos y vías verdes junto a patrimonio cultural y etnográfico. A lo que se añaden las 827 empresas de turismo activo registradas en Andalucía, que amplifican las oportunidades para ofrecer productos integrados de cicloturismo con otras modalidades de turismo activo. En este sentido, atendiendo al número de empresas de turismo activo, destacan las provincias de Málaga, Cádiz y Granada, como se aprecia en el cuadro 2. 

cicloturismo.

Cuadro 2. Empresas de Turismo activo y recursos relacionados con el cicloturismo en Andalucía.

\begin{tabular}{|c|c|c|}
\hline & $\begin{array}{l}\text { Empresas } \\
\text { turismo activo }\end{array}$ & Ejemplos de empresas relacionadas con cicloturismo \\
\hline Almería & 72 & Almeria Bike Tours, Mountain Biking Spain \\
\hline Cádiz & 199 & Pedalea Andalucía, \\
\hline Córdoba & 37 & Bike Subbética C.B., \\
\hline Granada & 122 & Mountain Bike Granada, \\
\hline Huelva & 44 & \\
\hline Jaén & 67 & \\
\hline Málaga & 209 & $\begin{array}{l}\text { Thebikeshuttle, Bike } 2 \text { Malaga Tours \& Rent,Bike } 2 \text { Malaga Tours \& } \\
\text { Rent, Electric Bike Malaga, Sierra Cycling, Espíritu Nómada Rutas } \\
\text { BTT, Centro Ciclismo Andalucía }\end{array}$ \\
\hline Sevilla & 77 & La Bicicleta Roja, Vía Viva \\
\hline Total & 827 & \\
\hline
\end{tabular}

Fuente: Elaboración propia a partir de Consejería de Turismo y Comercio (2014a).

\subsubsection{LA PLANIFICACIÓN TERRITORIAL Y LA BICICLETA EN ANDALUCÍA.}

El Plan de Ordenación del Territorio de Andalucía (POTA) considera elementos estratégicos del capital territorial al patrimonio natural y cultural, y por ende, constituyen una referencia básica para el desarrollo de planes territoriales de ámbito subregional, planes turísticos, urbanísticos y sectoriales. Entre éstos señala especialmente el papel de la red de espacios naturales protegidos, espacios paisajísticos, la red fluvial del Guadalquivir, las zonas húmedas y el sistema de ciudades patrimoniales, redes patrimoniales y bienes de interés cultural.

El desarrollo especifico del POTA en las zonas con mayor dinamismo territorial y económico se lleva a cabo mediante los Planes de Ordenación del Territorio de ámbito subregional, centrados en las áreas con mayores tensiones territoriales, esto es, grandes aglomeraciones urbanas y espacios turísticos del litoral, e interior andaluz. Los planes territoriales de carácter subregional contienen directrices para la puesta en valor de este capital territorial en materia turística y recreativa. Establecen normas y orientaciones relevantes para el desarrollo del cicloturismo, sobre todo, las que atañen a la ordenación de los sistemas de interés supramunicipal de espacios libres, miradores, adecuaciones recreativas, carreteras paisajísticas, carriles-bici, itinerarios recreativos, corredores litorales, parques fluviales, parques metropolitanos y parques comarcales.

La bicicleta implica ante todo movilidad sostenible. Y ésta afecta tanto a la movilidad de los habitantes en sus desplazamientos diarios habituales, como a la movilidad recreativa y deportiva, y la de visitantes y turistas. De ahí la importancia del Plan Andaluz de la Bicicleta (PAB) 2014-2020 para el desarrollo del cicloturismo, instrumento planificador básico para el desarrollo de infraestructuras ciclistas. Ya en

ISSN: 0212-8594 ISSN-e: 2340-2776.N№ DOI: http://dx.doi.org/10.12795/rea.2015.i32.04

REA 32 (2015):76-107

http://editorial.us.es/es/revista-de-estudios-andaluces 
2004, el Parlamento de Andalucía aprobó el Pacto Andaluz por la bicicleta, en el que se sentaban claramente las bases de lo que sería el futuro PAB: 1. "Tomar en consideración la necesidad de elaborar y aprobar medidas legislativas que garanticen la adaptación de las vías públicas de Andalucía al tráfico ciclista, de modo que todos y todas podamos ejercer con comodidad y seguridad el derecho a circular en bicicleta por ellas. Estas medidas deberían incluir: señalización adecuada, normas de diseño de la vía pública que la hagan apropiada a su uso por los ciclistas y, cuando ello sea necesario, la reserva de un espacio exclusivo para los ciclistas (carriles bici). 2. "Instar al Ejecutivo Andaluz para que inicie el diseño y puesta en uso de una Red Básica de Vías Ciclistas de Andalucía, tomando como punto de partida para ello la recuperación de la red de caminos rurales y vías pecuarias, así como la adecuación al uso ciclista de la red de carreteras comarcales. 3. "Instar al ejecutivo Andaluz a que contemple la inclusión de Planes Directores de la Bicicleta en los Planes Intermodales de Transporte y en los Planes de Ordenación del Territorio de las grandes Áreas Metropolitanas Andaluzas. Estos Planes Directores deberían considerar no sólo la creación de un viario adecuado para la bicicleta, sino también el desarrollo de campañas para su promoción como medio de transporte y la creación de infraestructuras para fomentar la intermodalidad bicicleta-transporte público."

EI PAB subraya que la intermodalidad entre la bicicleta y la red de transporte público está por desarrollar, al no existir criterios comunes de admisión de bicicletas en los vehículos, ni en el estacionamiento de bicicletas en los nodos de transporte público regional. No obstante, se prevé que en los pliegos para la renovación de concesiones se adopte como mejora la admisión de bicicletas. EI PAB considera las pendientes menores del $4 \%$ aptas para el desarrollo de la bicicleta, y prácticamente, de carácter disuasorio, las que superen el 6\%. En este contexto identifica cuatro aglomeraciones urbanas muy aptas, que son las aglomeraciones de Sevilla, Huelva, Granada y Bahía de Cádiz, con pendientes inferiores al $4 \%$ en sus zonas más habitadas.

En consonancia con las limitaciones orográficas, la Red Andaluza de Vías Ciclistas propuesta en el Plan Andaluz de la Bicicleta se compone de ocho ejes principales (mapa 2, en azul), condicionados en gran parte por la disposición longitudinal de Sierra Morena, Valle del Guadalquivir, Cordilleras Subbéticas y Béticas, y por la extensa franja litoral.

Dentro del sistemas de ciudades andaluzas principales destacan por la longitud de las vias ciclistas, destinos turísticos de importancia regional; en primer lugar, Sevilla, seguida de Córdoba, Málaga y Granada. Por lo que respecta a los ratios de vias ciclistas por habitante y vias ciclistas por plazas turísticas sobresalen, especialmente, Sevilla y Córdoba, si bien en diferentes medida, dedo a los mayores valores absolutos, tanto poblacionales como de plazas turisticas, de la ciudad hispalense.

ISSN: 0212-8594 ISSN-e: 2340-2776.N№ DOI: http://dx.doi.org/10.12795/rea.2015.i32.04

REA 32 (2015):76-107

http://editorial.us.es/es/revista-de-estudios-andaluces 
Cuadro 3. Vías ciclistas y turismo en ciudades andaluzas.

\begin{tabular}{|c|c|c|c|c|c|c|c|c|}
\hline Ciudad & $\begin{array}{l}\text { Vias } \\
\text { ciclistas } \\
\text { existentes } \\
\text { (m) } \\
\end{array}$ & $\begin{array}{l}\text { Vias ciclistas } \\
\text { existentes } \\
(\mathrm{m}) / \text { mil -hab. }\end{array}$ & \begin{tabular}{|l} 
Vias \\
ciclistas \\
ejecución \\
\end{tabular} & \begin{tabular}{|l|} 
Vias ciclistas \\
totales \\
(existentes \\
mas en \\
ejecución) \\
\end{tabular} & \begin{tabular}{|l} 
Vias \\
ciclistas \\
totales \\
$(\mathrm{m}) / \mathrm{mil}$ - \\
hab. \\
\end{tabular} & \begin{tabular}{|l} 
Vias \\
ciclistas \\
totales \\
$(\mathrm{m}) /$ plaza \\
turísticas \\
\end{tabular} & $\begin{array}{l}\text { Número } \\
\text { plazas } \\
\text { turisticas }\end{array}$ & $\begin{array}{l}\text { Población } \\
(2012)\end{array}$ \\
\hline Algeciras & 6.674 & 57,08 & 0 & 6.674 & 57,08 & 3,12 & 2.139 & 116.917 \\
\hline Almeria & 17.912 & 93,56 & 706 & 18.618 & 97,25 & 3,23 & 5.771 & 191.443 \\
\hline Cádiz & 8.769 & 70,75 & 0 & 8.769 & 70,75 & 3,47 & 2.525 & 123.948 \\
\hline Córdoba & 58.458 & 177,77 & 3.098 & 61.556 & 187,19 & 7,71 & 7.984 & 328.841 \\
\hline Granada & 22.779 & 95,30 & 5.301 & 28.080 & 117,48 & 1,73 & 16.222 & 239.017 \\
\hline Huelva & 15.744 & 105,97 & 0 & 15.744 & 105,97 & 14,92 & 1.055 & 148.568 \\
\hline Jaén & 7.831 & 67,09 & 0 & 7.831 & 67,09 & 7,40 & 1.058 & 116.731 \\
\hline Jérez de la Frontera & 15.076 & 71,15 & 7.182 & 22.258 & 105,04 & 5,68 & 3.921 & 211.900 \\
\hline Málaga & 44.521 & 78,46 & 3.959 & 48.480 & 85,44 & 4,63 & 10.472 & 567.433 \\
\hline Sevilla & 135.878 & 193,46 & 0 & 135.878 & 193,46 & 6,25 & 21.757 & 702.355 \\
\hline Total & 333.642 & 121,45 & 20.245 & 353.887 & 128,82 & 4,85 & 72.904 & 2.747 .153 \\
\hline
\end{tabular}

Fuente: Elaboración propia. Datos de vías ciclistas del Plan Andaluz de la Bicicleta. Datos de plazas turísticas y población de IECA (2014).

EI PAB contempla que la red de vías ciclistas de Andalucía impulsará el desarrollo del turismo sostenible en la comunidad autónoma de acuerdo con el Plan General de Turismo Sostenible de Andalucía. Entre sus objetivos se incluyen consolidar, coordinar e integrar las iniciativas cicloturísticas existentes; posibilitar la conformación de productos turísticos variados relacionados con la bicicleta en función de la longitud de su recorrido y su dificultad, o de la presencia de elementos de interés que caractericen las rutas propuestas, como por ejemplo, rutas monumentales, gastronómicas o paisajísticas; integrar la oferta cicloturística de la red de vías ciclistas a nivel autonómico con una oferta cicloturística a nivel metropolitano y urbano; y difundir la existencia de la red de vías ciclistas de Andalucía entre las empresas de cicloturismo para que puedan adaptar su oferta de servicios.

El programa turístico del PAB abarca una serie de medidas de importancia para el cicloturismo, como la conformación de recorridos turísticos en bicicleta con distinta temática, tanto para el ámbito regional como para el metropolitano y urbano, en el marco de la red de vías ciclistas de Andalucía; la creación de un distintivo de calidad para la bicicleta en Andalucía para las empresas de servicios turísticos y/o adecuación a distintivos existentes para su integración en redes de mayor difusión internacional; el establecimiento y mejora de la oferta de servicios para el turismo en bicicleta en aparcamientos, zonas de descanso, servicios especializados, hoteles, hostales, albergues, bares y restaurantes, talleres de bicicletas; y promoción de préstamos de bicicletas en establecimiento hoteleros; junto a la edición de una guía de turismo en Bicicleta por Andalucía, así como otras actividades de comunicación y difusión en redes sociales y con operadores turísticos.

Por su parte, el Plan General de Turismo Sostenible de Andalucía 2014-2020 recoge diversos programas cicloturistas (Ortega Palomo, G., 2014), tales como el "fomento de los modos de transporte no motorizados en los destinos turísticos, apoyando segmentos como el cicloturismo, implantación de empresas de servicios para 
cicloturistas en las ciudades, conectividad de entornos y recursos turísticos mediante la creación de itinerarios o rutas turísticas, adecuando senderos y caminos para uso peatonal y/o en bicicleta". Asimismo establece actuaciones de colaboración con la Consejería de Fomento, en el marco del Plan Andaluz de la Bicicleta, dirigidas al fomento a nivel regional del cicloturismo, desarrollo de la ruta mediterránea y de la costa Atlántica de la red Eurovelo, y de los productos cicloturistas asociados a la misma". Finalmente, prevé un programa de complementariedad entre segmentos, destinos y productos turísticos para "la práctica del cicloturismo, el senderismo y el turismo ecuestre de la red andaluza de Vías Verdes, producto turístico con potencial para dinamizar un territorio y para generar sinergias con otros segmentos y productos: gastronomía, cultura, naturaleza".

\subsection{CONTEXTO GENERAL DE LOS MACROFLUJOS TURÍSTICOS EN ESPAÑA Y ANDALUCÍA.}

El conocimiento de los factores explicativos del capital territorial que se asocian con los flujos turísticos reviste interés, tanto desde una perspectiva teórica, como aplicada, para el diseño de estrategias de los diferentes segmentos turísticos, y en especial del cicloturismo. El cuadro 4 resume las asociaciones estadísticas significativas identificadas en las comunidades autónomas españolas. Se aprecia en primer lugar la alta correlación de las pernoctaciones hoteleras en las comunidades autónomas con el capital litoral, medido por la longitud de la costa ( $r=0.738$ ), y de forma más moderada, aunque también significativa, con el número de bienes de interés cultural ( $r=0.674)$, y la superficie relativa de espacios naturales protegidos $(r=0.520)$.

Andalucía se ajusta particularmente bien a la recta obtenida en la correlación de las pernoctaciones hoteleras con los kilómetros de costa (figura 1), lo que denota una intensa asociación del turismo con este recurso geográfico. Los valores más elevados de pernoctaciones hoteleras se alcanzan en las comunidades insulares (Canarias y Baleares), donde predomina el turismo litoral, seguidas de Cataluña y Andalucía. Cataluña se distancia algo más de la recta de regresión, indicio de una menor dependencia del turismo litoral, posiblemente por una mayor diversificación de tipologías y productos turísticos. Este distanciamiento estadístico es mucho más acusado en el caso de Galicia, comunidad dotada de una amplia costa, si bien con un clima atlántico menos adecuado para el baño. En cualquier caso, las correlaciones ponen de manifiesto el protagonismo del litoral como gran fuerza motriz de los flujos turísticos en España y Andalucía, y en menor medida, con el capital cultural y natural. Estos resultados difieren de los obtenidos en las regiones de Italia por Pompili y Martinoia, (2011). No obstante, guardan relación en la medida que estos autores detectaron una asociación del capital cultural con el empleo turístico, variable presumiblemente dependiente del número de pernoctaciones en la región. Por otro lado, el número de pernoctaciones de turistas nacionales en establecimientos andaluces se asocia con el capital demográfico de la comunidad autónoma emisora $(r=0.736)$, lo que denota la importancia del tamaño poblacional del mercado emisor. 
Es la propia comunidad andaluza la que obtiene mayores pernoctaciones en establecimientos hoteleros en Andalucía, en consonancia con su mayor peso poblacional, si bien otras variables, como la distancia y la renta per cápita puedan intervenir.

Las correlaciones obtenidas sugieren que los recursos vinculados con la costa, bienes de interés cultural y espacios naturales protegidos -asociados estadísticamente con los movimientos turísticos- deben ser objeto de especial atención. Andalucía destaca significativamente en la dotación de estos recursos territoriales, por tanto, el mercado potencial cicloturístico vinculado a estos grandes flujos turísticos debe considerarse singularmente en el diseño y comercialización de productos cicloturísticos, así como de infraestructuras ciclistas. En concreto, incrementando la oferta de productos cicloturísticos en torno al litoral para un amplio espectro de perfiles. Esto es, con una oferta no exclusiva de cicloturistas de montaña y deportivos, que incluya una gama más amplia y "convencional" de turistas potencialmente interesados en actividades ciclistas, de mayor o menor intensidad.

Es presumible que aquellos espacios en los que converjan litoral, espacios naturales protegidos y bienes de interés cultural presentarán especiales aptitudes para el desarrollo del cicloturismo, sin menoscabo de su desarrollo en el interior. En el caso de los cicloturistas de montaña los aspectos mejor valorados en la elección del destino son principalmente discurrir por buenos paisajes y espacios protegidos donde observar fauna y flora silvestre, además de aspectos gastronómicos, monumentales y culturales (Andalbike, 2014).

Por último, la elevada correlación del uso del transporte público con la densidad poblacional ( $r=0.858)$ parece apuntar en favor de las ventajas de las economías de aglomeración y la compacidad espacial. En esta casuística destacan Madrid y Cataluña, por ser comunidades emisoras de turistas a Andalucía densamente pobladas y con uso frecuente del transporte público. Consiguientemente, la intermodalidad del transporte público con la bicicleta, y el desarrollo del cicloturismo, será especialmente eficaz en territorios densamente poblados, con turistas habituados al uso de la bicicleta y al transporte público. 
Flujos turísticos, capital territorial y uso de la bicicleta. Andalucía como modelo de destino emergente en cicloturismo.

Figura 1. Diagramas de dispersión de las correlaciones de las pernoctaciones hoteleras con los km de costa, bienes de interés cultural y población. Correlación entre el \% de transporte público y la densidad poblacional.
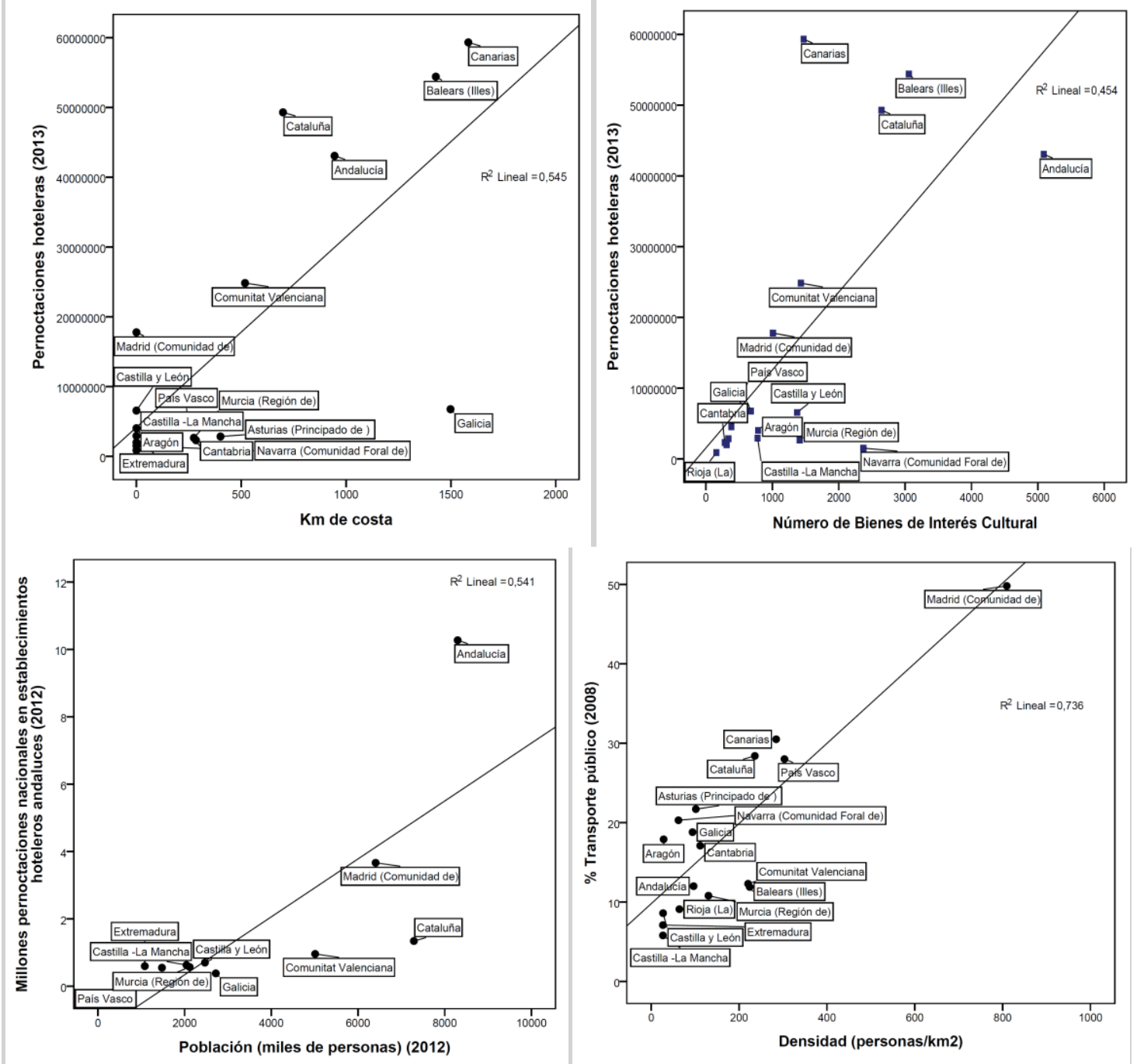

Fuente: Elaboración propia

ISSN: 0212-8594 ISSN-e: 2340-2776.№ DOI: http://dx.doi.org/10.12795/rea.2015.i32.04

REA 32 (2015):76-107

http://editorial.us.es/es/revista-de-estudios-andaluces 
Cuadro 4. Correlaciones estadísticas obtenidas.

\begin{tabular}{|l|l|l|l|l|l|l|}
\hline & $\begin{array}{l}\text { Km de } \\
\text { costa }\end{array}$ & $\begin{array}{l}\text { Número de } \\
\text { Bienes de } \\
\text { Interés Cultural }\end{array}$ & $\begin{array}{l}\text { Superficie } \\
\text { espacios naturales } \\
\text { protegido/1.000 } \\
\text { ha (2010) }\end{array}$ & $\begin{array}{l}\text { Población } \\
\text { (2013) }\end{array}$ & $\begin{array}{l}\text { Población } \\
\text { (2012) }\end{array}$ & $\begin{array}{l}\text { Densidad } \\
\text { de } \\
\text { población }\end{array}$ \\
\hline $\begin{array}{l}\text { Pernoctaciones hoteleras } \\
\text { nacionales e } \\
\text { internacionales (2013) }\end{array}$ & $\begin{array}{l}\mathrm{r}=0.738^{* *} \\
\text { Sig. } 0.001\end{array}$ & $\begin{array}{l}\mathrm{r}=0.674^{* *} \\
\text { Sig. } 0.003\end{array}$ & $\begin{array}{l}\mathrm{r}=0.572^{*} \\
\text { Sig. } 0.016\end{array}$ & $\begin{array}{l}\mathrm{r}=0.520^{*} \\
\text { Sig. } 0.032\end{array}$ & & \\
\hline $\begin{array}{l}\text { Pernoctaciones nacionales } \\
\text { en establecimientos } \\
\text { hoteleros andaluces (2012) }\end{array}$ & & & & $\begin{array}{l}\mathrm{r}=0.736^{*} \\
\text { Sig. } 0.015\end{array}$ & \\
\hline $\begin{array}{l}\text { \% Transporte público } \\
\begin{array}{l}\text { Comunidad Autónoma } \\
\text { (2008) }\end{array}\end{array}$ & & & & & & $\begin{array}{l}\mathrm{r}=0.858^{* *} \\
\text { Sig. } 0.000\end{array}$ \\
\hline
\end{tabular}

Fuente: Elaboración propia. ${ }^{* *}$ : Significativo al $1 \%{ }^{*}$ : Significativo al $5 \%$. (2 colas).

\subsection{CONTEXTO PARTICULAR DEL MERCADO CIClOTURíStICO. PANORAMA Y TENDENCIAS.}

En los últimos años se ha observado un incremento gradual del cicloturismo en numerosos paises (Meschik, M., 2012), y un crecimiento notable en Norteamerica durante las dos últimas décadas (Pucher, J., Buehler, R., \& Seinen, M., 2011). Este crecimiento se ha mantenido incluso en periodos de intensa crisis económica como la experimentada recientemente (Zovko, I., 2013). Se espera además un incremento continuado del mercado cicloturista (Mintel, 2009; Weston et al., 2012). Esta previsión es relevante debido al efecto económico multiplicador del cicloturismo, estimado en torno a 1,57 en Escocia (Zovko, I., 2013). A este efecto habría que sumar el positivo impacto sobre la salud de las personas, con el consiguiente ahorro de gastos sanitarios. La relación coste-beneficio de la actividad física en bicicleta y pedestre es de 2,94 , lo que significa que de cada dólar invertido se obtiene un beneficio sanitario de 2,94 dólares (Wang, G., et al., 2005).

Diversos factores e intervenciones se consideran claves en el auge de la bicicleta, en particular, la provisión de infraestructuras adecuadas, programas y planes para el apoyo de la bicicleta, junto a restricciones en el uso indiscriminado del vehículo privado (Pucher, J.; Dill,J., Handy, S., 2010); y en suma, el empleo de un amplio rango de políticas públicas de soporte (Pucher, J., Buehler, R., 2007).

Los servicios y entornos amigables para el cicloturismo resultan esenciales. En países con gran tradición ciclista como Alemania existe una amplia oferta con distintivos de calidad para servicios amigables con el cicloturista: Bett \& Bike de ADFC, alojamientos de hoteles y gastronomía especializada para ciclistas (Fahrradfreundlicher Hotel- und Gaststättenbetrieb), talleres especializados, así como una extensa gama de paquetes de cicloturismo, en la que destaca además la diversidad de modelos de bicicletas ofertados en función del perfil de cada turista (Bundesministerium für Wirtschaft und 
Technologie, 2009). La integración de la bicicleta con el tren se encuentra muy avanzada, con programas específicos como Bahn \& Fahrrad", Bahn \& Bike international" $y$ "Call a Bike".

En Europa diferentes programas lideran la consolidación de productos de cicloturismo, como el proyecto de creación del producto vías verdes ("Greenways Product"), financiado por la Unión Europea (European Greenways Association, 2014). Este producto incide especialmente en las fortalezas de las vías verdes por su accesibilidad, seguridad y universalidad de usuarios; sin apenas limitaciones de edad o capacidad física. Las rutas transnacionales europeas se promocionan fundamentalmente a través de la Red Eurovelo, iniciativa de cooperación transnacional, coordinada por la Federación Ciclista Europea. En Andalucía destacan la ruta mediterránea y la de la costa atlántica (EuroVelo - the European Cycle Route Network, 2014)). La red está proyectada en su configuración actual en torno a 66.000 kilómetros, de los que se estima unos 20.000 se encuentran en funcionamiento. Otro proyecto desarrollado de ámbito europeo es Revermed, cuyo fin es conformar una ruta de larga distancia entre Portugal, España, Francia e Italia (Weston, 2012).

El papel de las ciudades para el desarrollo del cicloturismo es de primer orden. De hecho, muchos de los grandes destinos europeos invitan más al uso de la bicicleta y los desplazamientos a pie que al uso del coche, gracias a la implementación de políticas de ciclabilidad para turistas y residentes. Este es el caso de Paris, Sevilla, Ámsterdam, Barcelona Berlín, Budapest, Copenhague y Lyon (Weston et al, 2012). En esta línea se asienta la cooperación de comunidades ciclables en el mundo (Red de Ciudades por la Bicicleta, 2011), una iniciativa integrada por la red de ciudades activas de Velo Quebec (Canadá), Bycicle Friendly Communities (Estados Unidos), Club de Villes et Territoires Cyclables (Francia) y la red de Ciudades por la Bicicleta (España), dirigido a promover el uso de la bicicleta con fines de transporte, recreo, deporte y turismo a nivel internacional. Entre los miembros asociados a la Red de Ciudades por la Bicicleta figuran Córdoba, el Ayuntamiento de Sevilla, el Consorcio de Transporte Metropolitano del Área de Sevilla, y el Ayuntamiento de Tarifa (Red de Ciudades por la Bicicleta, 2014). Una buena práctica, beneficiosa tanto para residentes como para turistas, es el empleo de un sistema de bicicletas públicas de alquiler en las ciudades. En España estos servicios se encuentran en fase de expansión. En el ámbito andaluz comprenden las ciudades de Algeciras, Dos Hermanas, Jerez de la Frontera y Sevilla.

La imagen de ciudad amigable para turistas y residentes depende de los equipamientos existentes para la bicicleta, y muy especialmente, de la cultura ciclista local, como parte del capital territorial. Dado la intangibilidad del servicio y la facilidad de imitar innovaciones no tecnológicas, ni protegibles mediante patente en turismo (Fernández-Latorre, F.M., 2012), el refuerzo de la marca turística resulta primordial. Por este motivo, la dotación de carril bici se está utilizando como indicador de

ISSN: 0212-8594 ISSN-e: 2340-2776.№ DOI: http://dx.doi.org/10.12795/rea.2015.i32.04 
competitividad de destinos turísticos urbanos, recogido en el monitor Urban TUR (cuadro 5).

La identidad turística de ciudades y territorios encuentra así un poderoso aliado en el uso de la bicicleta. Ciudades turísticas como Ámsterdam y Copenhague son reconocidas internacionalmente por su imagen ligada a la bicicleta (Pucher, J., Buehler, R., 2007). En Copenhague la tasa de uso de la bicicleta en 2010 fue del 36\%, y para el año 2015 se pretende alcanzar el 50\% (The City of Copenhague, 2014). En esta ciudad, el $48 \%$ de los ciclistas afirman que el principal motivo para utilizar la bicicleta es por su mayor rapidez, claramente visible en la imagen de la figura 2.

Las expectativas del cicloturismo en ciudades turísticas son evidentes considerando las predicciones de crecimiento del turismo urbano mundial. Las tendencias

Cuadro 5. Carril bici en ciudades turísticas españolas.

\begin{tabular}{|l|r|r|r|}
\hline & & & Km carril-bici/1000 habitantes \\
\hline Barcelona & km carril bici (2012) & Población (2011) & 0,11 \\
\hline Valencia & 181,5 & 1.611 .013 & 0,18 \\
\hline Sevilla & 145,0 & 792.054 & 0,20 \\
\hline Zaragoza & 142,0 & 698.042 & 0,15 \\
\hline Madrid & 104,0 & 678.115 & 0,03 \\
\hline Bilbao & 103,8 & 3.198 .645 & 0,22 \\
\hline Alicante & 78,0 & 351.356 & 0,15 \\
\hline Burgos & 50,0 & 329.325 & 0,23 \\
\hline San Sebastián & 41,0 & 178.864 & 0,19 \\
\hline Córdoba & 36,0 & 185.512 & 0,09 \\
\hline Málaga & 31,0 & 328.326 & 0,05 \\
\hline Salamanca & 26,8 & 561.435 & 0,15 \\
\hline Gijón & 23,0 & 151.658 & 0,07 \\
\hline Santander & 19,5 & 276.969 & 0,10 \\
\hline La Coruña & 17,5 & 178.095 & 0,06 \\
\hline León & 15,0 & 245.053 & 0,11 \\
\hline Toledo & 14,0 & 131.411 & 0,05 \\
\hline Total & 4,0 & 83.872 & 0,10 \\
\hline
\end{tabular}

Fuente: Elaboración propia. Datos de Km carril bici de Excelltur a partir de información municipal (Urban TUR 2012), Población: INE, censo 2011.

registradas constatan el incremento continuo del turismo de ciudad (city trips), incrementado en un 47\% desde 2009 (ITB, 2013). Esta misma fuente considera a China como el mayor mercado emergente del mundo, con un crecimiento de viajes al extranjero del $26 \%$ en 2013. Este poderoso emisor turístico considera Europa un atractivo destino turístico por su gran diversidad de atractivos naturales y culturales. Datos todos estos a considerar en las políticas de diversificación de perfiles turísticos en el viejo continente, incluido el cicloturismo.

ISSN: 0212-8594 ISSN-e: 2340-2776.N№ DOI: http://dx.doi.org/10.12795/rea.2015.i32.04 
Figura 2. La imagen y competitividad de la bicicleta en Copenhague.

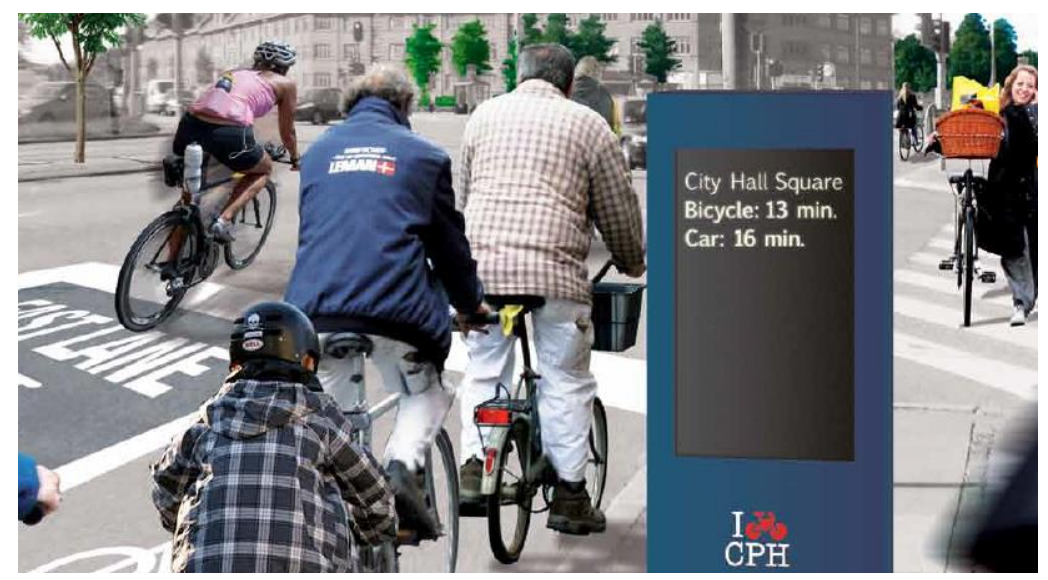

Fuente: The City of Copenhagen (2014).

En el ámbito nacional, el Barómetro anual de la bicicleta en España muestra un aumento en la concienciación de los beneficios de la bicicleta, que utilizan un $20 \%$ de los españoles al menos una vez a la semana, y la práctica unanimidad de los encuestados a favor del fomento de ésta, por parte de la administración (Fundación ECA Bureau Veritas- Dirección General de Tráfico, 2011). Así todo, el uso de la bicicleta como forma de transporte principal de los españoles es todavía claramente marginal, muy inferior al empleo del transporte público, y aún más, respecto al uso del vehículo privado. A nivel nacional destacaban regiones turísticas como Baleares, Cataluña y Murcia en el uso de la bicicleta, y las comunidades autónomas de Madrid, Cataluña y Canarias en el empleo del transporte público, según datos disponibles del INE para el año 2008.

Pero precisamente por estos motivos, el potencial de crecimiento del cicloturismo en España es superior a la media europea, puesto que se ha empezado más tarde a estructurar la oferta, y el uso diario de la bicicleta es inferior a la media (Mato i Palos, E. y Troyano, X., 2014). Cuantitativamente, el cicloturismo es uno de los subsegmentos del turismo deportivo con más perspectivas de crecimiento (Consejería de Comercio y Turismo, 2013). No obstante, son necesarias campañas de sensibilización dirigidas a empresarios operadores locales para atender las demandas y requerimientos del cliente cicloturista, por ejemplo, espacios en los hoteles donde guardar adecuadamente las bicicletas, aparcabicis junto a los restaurantes, etc. (Fundación de Ferrocarriles Españoles, 2008). Del análisis de Weston et al. (2012) se concluye que los cicloturistas valoran sobre todo la seguridad y continuidad de las rutas, espacios naturales agradables y pueblos y ciudades apacibles para las bicicletas, así como una señalización e información interpretativa clara (Mato i Palos, E. y Troyano, X., 2014). Servicios especializados como Bed\&Bike, Bicicly friendly, y empresas como bikespain, Pangea, o incluso de ámbito mundial como Biketours, se encuentran en expansión. 

cicloturismo.

El litoral ofrece condiciones excelentes para la práctica cicloturista y constituye un recurso clave en el desarrollo del cicloturismo, tal como se ha expuesto en el apartado anterior de correlaciones estadísticas. E igualmente, como se ha señalado, es la comunidad balear la que registra un mayor uso de la bicicleta como medio de transporte principalmente utilizado por los habitantes (cuadro 6). Mallorca, por su parte, recibe unos 90.000 cicloturistas al año, con estancias de una semana aproximadamente, centradas en el periodo de marzo a junio (VisitMallorca, 2014). Estos datos son coherentes con el peso del turismo alemán, de gran tradición ciclista. Por otra parte, grandes compañías de cruceros empiezan a ofrecer servicios ligados al cicloturismo litoral, caso de los "planes con bici" (Trasmediterranea, 2014), cruceros con bici en Holanda (Holanda Natural, 2014), y la empresa Tripsite, especializada en viajes en bicicleta y barco por Europa y Asia, tours en bici por Estados Unidos y cruceros fluviales de lujo por Europa, Asia y Sudamérica (Amazonas).

La innovación en el cicloturismo y la bicicleta dispone de un amplio margen de crecimiento. Un ejemplo es el empleo creciente de la bicicleta eléctrica, que permite

Cuadro 6. Porcentajes de uso del transporte público y de la bicicleta como medios de transporte principalmente utilizado, en las comunidades autónomas (2008).

\begin{tabular}{|c|c|c|}
\hline & \% Transporte público (2008) & \% Bicicleta (2008) \\
\hline Andalucía & 12 & 1,5 \\
\hline Aragón & 17,9 & 1 \\
\hline Asturias & 21,7 & 0,3 \\
\hline Balears (Illes) & 11,9 & 2,8 \\
\hline Canarias & 30,5 & 0,9 \\
\hline Cantabria & 17,1 & 0,4 \\
\hline Castilla y León & 8,6 & 1,7 \\
\hline Castilla -La Mancha & 5,8 & 1,4 \\
\hline Cataluña & 28,4 & 2 \\
\hline Comunitat Valenciana & 12,3 & 1,6 \\
\hline Extremadura & 7,1 & 0,7 \\
\hline Galicia & 18,8 & 0,4 \\
\hline Madrid (Comunidad) & 49,8 & 0,3 \\
\hline Murcia (Región) & 10,8 & 2,3 \\
\hline Navarra & 20,3 & 0,9 \\
\hline País Vasco & 28 & 1,1 \\
\hline Rioja (La) & 9,1 & 1,1 \\
\hline
\end{tabular}

Fuente: Elaboración propia a partir de INE (2008).

superar limitaciones impuestas por grandes pendientes o la condición física del ciclista, y por tanto, alargar las distancias. En efecto, las bicicletas eléctricas, e-bike o pedelecs están experimentando crecimientos muy altos en Europa, y han pasado de 100.000 ventas registradas en 2005 a 400.000 en 2009 (Fundación RACC, 2010). Europa es el segundo mercado mundial en ventas de bicicletas eléctricas (después de China), con

ISSN: 0212-8594 ISSN-e: 2340-2776.№ DOI: http://dx.doi.org/10.12795/rea.2015.i32.04

REA 32 (2015):76-107

http://editorial.us.es/es/revista-de-estudios-andaluces 
un millón de ventas en 2013 y una previsión de 1,9 millones para 2020 (Navigant Research, 2013). El clima de Andalucía, muy favorable para el uso de la bicicleta durante todo el año, dificulta sin embargo los grandes recorridos durante los periodos más calurosos, incrementando la fatiga y el sudor. En estas condiciones, las bicicletas eléctricas pueden ser de ayuda, especialmente para los segmentos de población de mayor edad o menor forma física.

Las posibilidades de innovación de la bicicleta por adaptación a los segmentos turísticos existentes son múltiples. Como muestra, la adaptación de la bicicleta a los campos del golf, dotadas de ruedas especiales para minimizar el impacto sobre el césped, con capacidad para transportar el set de palos de golf y adaptarse a las pendientes (Costa del Sol Golf Club, 2014). Otra evidencia del potencial de crecimiento del sector es la constitución de la Plataforma Empresarial de la Bicicleta, cluster de la bicicleta en España, que persigue aglutinar las actividades empresariales en este campo, tanto en el proceso de fabricación, como en otras facetas de la bicicleta que constituyan una parte importante de la actividad empresarial (Plataforma Empresarial de la Bicicleta, 2014).

El perfil del turista que visita Andalucía con mayor afinidad para desarrollar actividades cicloturistas viene condicionado en primera instancia por el grado de utilización de la bicicleta en su país o comunidad de origen. Combinando este dato con el número de turistas o pernoctaciones en Andalucía, es posible obtener una primera aproximación de la estructura del mercado potencial del cicloturismo en función de su procedencia. La figura 3 apunta al mercado alemán como gran nicho cicloturista a desarrollar en Andalucía, junto a Francia y Reino Unido, seguido de los países nórdicos, Holanda y Bélgica. En cuanto al mercado nacional (figura 4), es destacable el alto número de pernoctaciones con origen en la propia comunidad andaluza, así como de turistas procedentes de la Comunidad de Madrid y de Cataluña, ésta última de gran tradición ciclista. En cuanto a la distribución porcentual de turistas recibidos según nacionalidades, Andalucía registra cuotas relativas mayores que el conjunto nacional en el caso del mercado británico; y menores en dos mercados cicloturísticos potentes: el mercado francés y el mercado alemán (figura 3). Sin embargo, Andalucía se posiciona por encima de España como destino de los países nórdicos y Holanda, ambos con una gran cultura cicloturista. 
Flujos turísticos, capital territorial y uso de la bicicleta. Andalucía como modelo de destino emergente en cicloturismo.

Figura 3. Miles de turistas en Andalucía y \% de uso de la bicicleta en el país emisor.

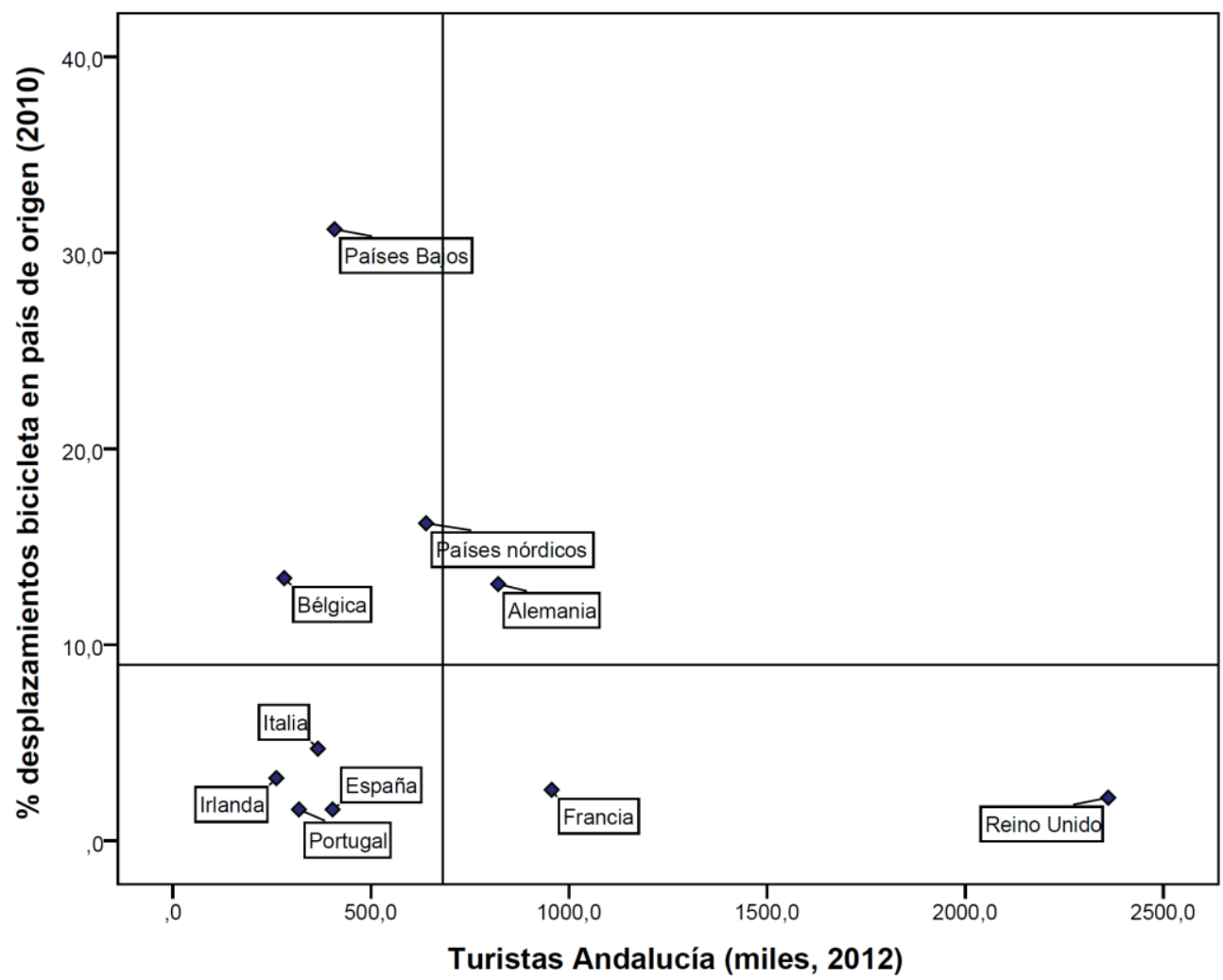

Fuente: Elaboración propia a partir de The Gallup Organization. (2011) y Frontur (2014).

Figura 4. \% de turistas según países emisores en Andalucía y España (2012).

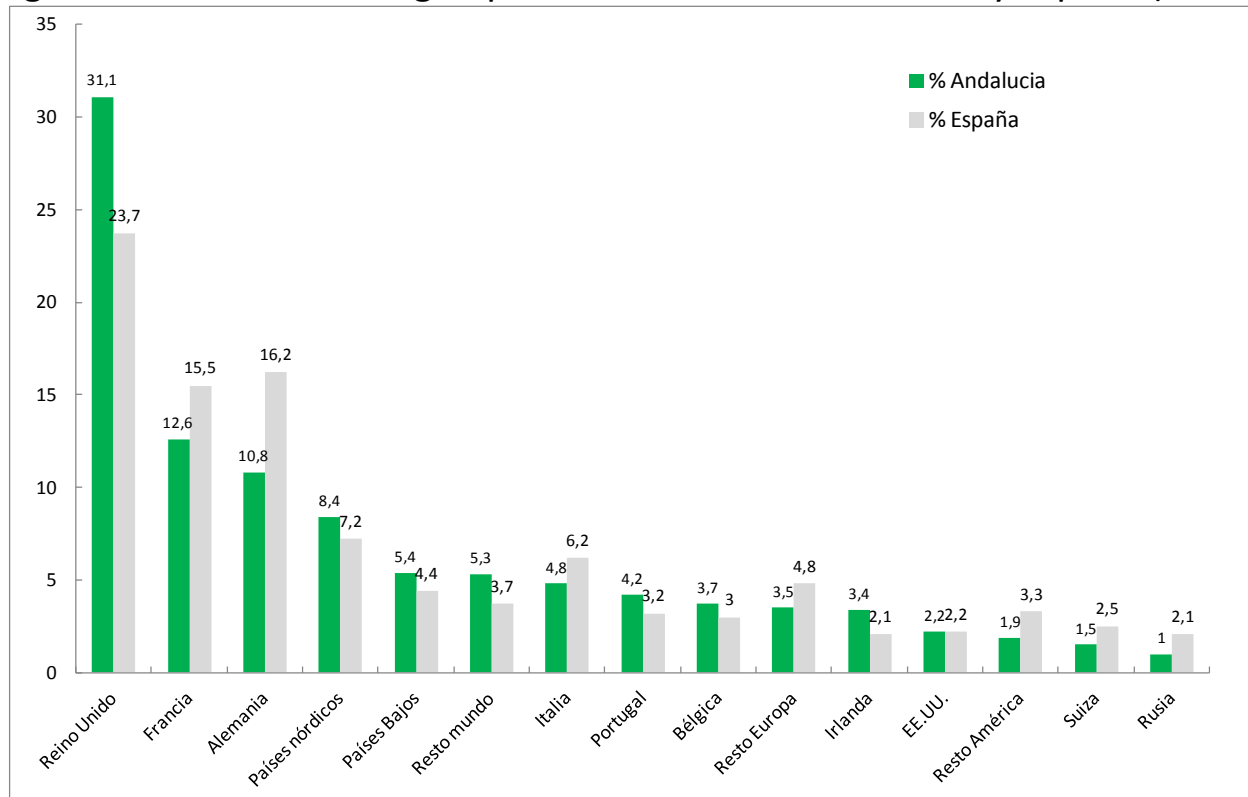

Fuente: Elaboración propia a partir de Movimientos Turísticos en Fronteras (Frontur, 2014).

ISSN: 0212-8594 ISSN-e: 2340-2776.№ DOI: http://dx.doi.org/10.12795/rea.2015.i32.04

REA 32 (2015):76-107

http://editorial.us.es/es/revista-de-estudios-andaluces 

cicloturismo.

Figura 5. Pernoctaciones hoteleras nacionales en Andalucía y uso de la bicicleta en la comunidad de origen.

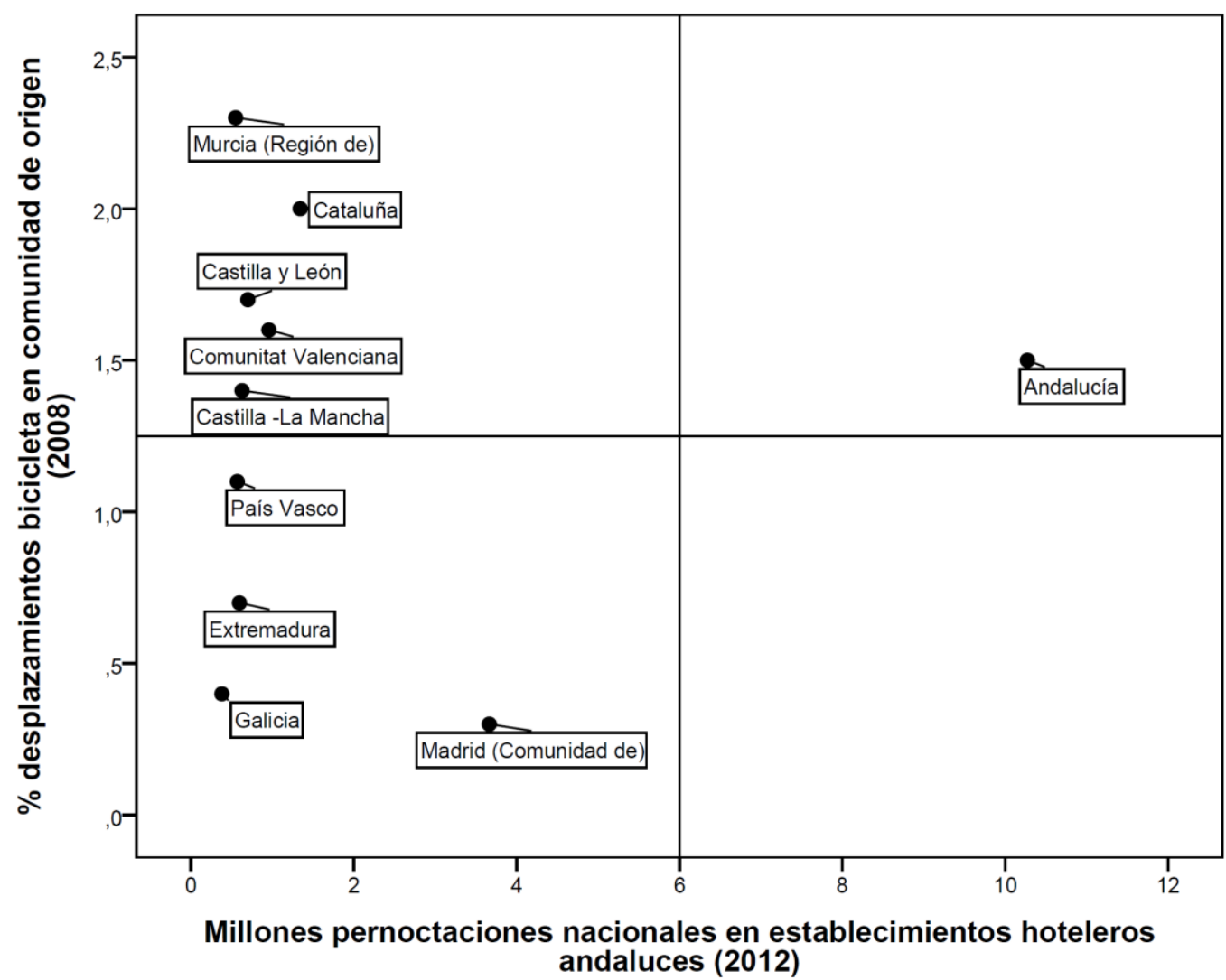

Fuente: Elaboración propia a partir de Frontur (2014) e INE (2008).

\subsection{MODELO MULTIDIMENSIONAL DEL CICLOTURISMO.}

El modelo convencional de cicloturismo está orientado, y polarizado a menudo, hacia el perfil deportivo de ciclista entusiasta, o "cicloturismo duro" . Como resultado, el cicloturismo es claramente minoritario, y con frecuencia se ignora un grupo cuantitativamente muy importante de perfiles intermedios, constituido por personas amantes de la bicicleta, dispuestas a desarrollar actividades cicloturísticas de una forma mas moderada ("cicloturismo blando"), en combinación con otros recursos turísticos.

En contraposición, el modelo multidimensional que se propone concibe la actividad cicloturística como un instrumento para combinar los diferentes recursos turísticos del capital territorial, presentes en diferentes destinos, en distintas intensidades y dimensiones espaciales. La idea es que las infraestructuras ciclistas deben conectar los principales nodos turísticos (incluyendo tanto las atracciones turísticas como las instalaciones de alojamiento) y poblacionales con los principales nodos de transporte intermodal, mejorando a su vez la conectividad ecológica de especies y hábitats, tanto en areas rurales como urbanas. Las cuatro dimensiones básicas que conforma el

ISSN: 0212-8594 ISSN-e: 2340-2776.N№ DOI: http://dx.doi.org/10.12795/rea.2015.i32.04 
modelo son i. Conectividad ciclista y ecológica, ii. Creación de imagen y marca, iii. Adaptación a los flujos turísticos existentes, y iv. Valorización del capital territorial en su conjunto (cuadro 7).

El desarrollo del cicloturismo debe ser capaz de aprovechar y adaptarse a los flujos turísticos presentes, junto al capital territorial de base que lo ha conformado, sea la presencia de un litoral extenso, una gran ciudad cultural u otra gran atracción. Las infraestructuras y servicios ciclistas en este modelo lógicamente han de estar presentes en los nodos de transporte públicos más sostenibles, como estaciones de trenes, puertos y estaciones de autobuses, pero también en aeropuertos, grandes aparcamientos urbanos para vehículos privados, y equipamientos culturales y de servicios. Diversos estudios muestran que las infraestructuras ciclistas y pedestres atraen turistas e incluso empresas (Alliance for Biking \& Walking, 2012), por lo que estos equipamientos ciclistas, y la imagen que representan, desempeñan una función estratégica frecuentemente minusvalorada.

En este modelo, el uso de la bicicleta en las ciudades turísticas es favorecido por incluir nodos turísticos situados a distancias moderadas, en las que la bicicleta resulta muy competitiva, lo que "permite ver más cosas" durante la visita. A su vez, este conjunto de nodos se integra con los nodos ecológicos, potenciando la conectividad ecológica y los servicios ecosistémicos mediante infraestructuras verdes (Commission of the European Communities, 2013), como vías pecuarias y vías verdes acondicionadas a tal fin.

Cuadro 7. Dimensiones del modelo para el desarrollo del cicloturismo.

\begin{tabular}{|c|c|}
\hline Dimensión & Cuestiones básicas a verificar/desarrollar \\
\hline $\begin{array}{l}\text { i. Conectividad ciclista } \\
\text { y ecológica }\end{array}$ & $\begin{array}{l}\text { 1. ¿Se han habilitado las vías ciclistas y su entorno para mejorar la conectividad } \\
\text { de especies y hábitats de interés en entornos sensibles? } \\
\text { 2. ¿Se identifican y priorizan pasillos cicloturistas potenciales y futuros? }\end{array}$ \\
\hline $\begin{array}{l}\text { ii. Creación de imagen } \\
\text { y marca }\end{array}$ & $\begin{array}{l}\text { 3. ¿Las actuaciones para el desarrollo del cicloturismo se llevan a cabo bajo } \\
\text { criterios unitarios de imagen? } \\
\text { 4. ¿Favorecen la creación de una marca de destino amigable con el } \\
\text { cicloturismo? } \\
\text { 5. ¿Se adopta alguna estructura jurídica independiente para garantizar el } \\
\text { cumplimiento de requisitos y estándares de calidad, así como la } \\
\text { comercialización conjunta? }\end{array}$ \\
\hline $\begin{array}{l}\text { iii. Adaptación a los } \\
\text { flujos turísticos } \\
\text { existentes }\end{array}$ & $\begin{array}{l}\text { 6. ¿Se implantan productos e infraestructuras turísticas adaptadas a los } \\
\text { principales flujos turísticos dentro del destino? } \\
\text { 7. ¿Existen áreas turísticas relevantes con déficit de infraestructuras ciclistas y } \\
\text { productos cicloturísticos? } \\
\text { 8. ¿Se tienen en cuenta los hábitos y preferencias de los turistas en el uso de la } \\
\text { bicicleta en su región de origen? }\end{array}$ \\
\hline $\begin{array}{l}\text { iv. Valorización del } \\
\text { capital territorial en su } \\
\text { conjunto }\end{array}$ & $\begin{array}{l}\text { 9. ¿Se integran recursos turísticos de diferentes tipologías (naturales, } \\
\text { culturales, empresariales.) y escalas? } \\
\text { 10. ¿Se adaptan de forma intermodal las infraestructuras ciclistas y de } \\
\text { transporte para el uso compartido de turistas y habitantes locales? }\end{array}$ \\
\hline
\end{tabular}

Fuente: Elaboración propia.

ISSN: 0212-8594 ISSN-e: 2340-2776.№ DOI: http://dx.doi.org/10.12795/rea.2015.i32.04

REA 32 (2015):76-107

http://editorial.us.es/es/revista-de-estudios-andaluces 
Esto implica enlazar los nodos turísticos y poblacionales con infraestructuras verdes diseñados en la doble vertiente de corredores ciclistas y corredores ecológicos. El resultado final es hacer "más ciclable" la naturaleza, y "más ecológicas" las vías ciclistas y su entorno. Para alcanzar estos objetivos es necesario diseñar e implementar un conjunto de normativa y regulaciones específicas, así como acciones en materia de investigación y desarrollo, monitorización y adaptación de infraestructuras ciclistas actuales y futuras, especialmente en áreas ecológicas sensibles altamente frecuentadas o degradadas.

Un principio básico del modelo es, por un lado, la hipersegmentación de productos cicloturistas, atendiendo a muy diversos grados de dificultad, y diferentes perfiles temáticos y socioeconómicos. Y por otro, facilitar la miscibilidad con productos cruzados de turismo, como turismo cultural, urbano, de congresos, de sol y playa, rural, de naturaleza, cruceros, náutico, de salud, deportivo, turismo accesible, turismo activo, turismo fotográfico, y de peregrinación. El resultado final esperado es el aumento de sensibilización y uso de la bicicleta por parte de turistas y habitantes, no solo durante las vacaciones, sino a lo largo de todo el año.

Figura 6. Modelo multidimensional de cicloturismo.

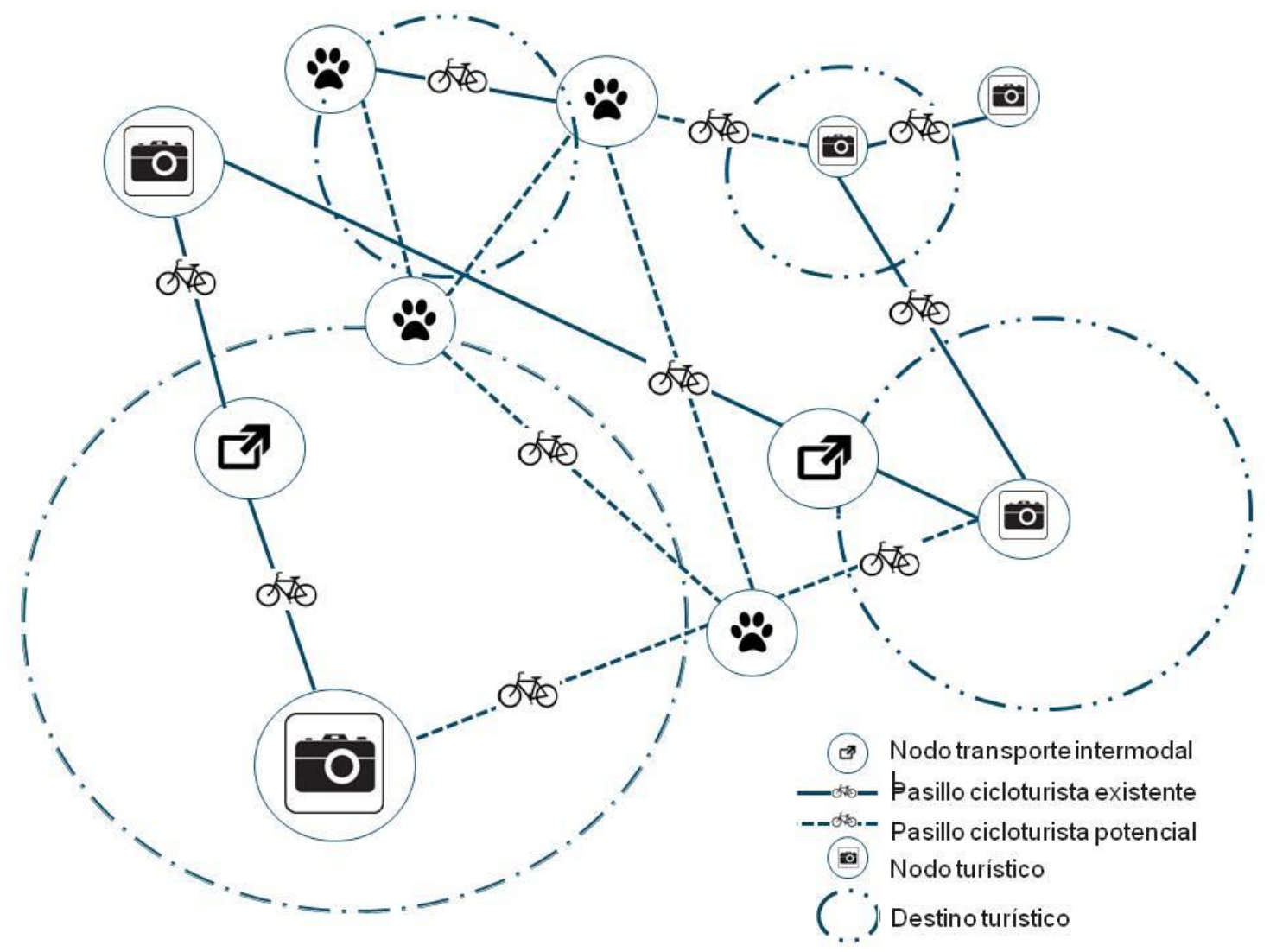

Fuente: Elaboración propia

ISSN: 0212-8594 ISSN-e: 2340-2776.N№ DOI: http://dx.doi.org/10.12795/rea.2015.i32.04

REA 32 (2015):76-107

http://editorial.us.es/es/revista-de-estudios-andaluces 


\section{CONCLUSIONES.}

El trabajo relaciona la dotación de recursos naturales y culturales con el cicloturismo, desde la perspectiva del capital territorial. Los resultados muestran una asociación estadística de la dotación de recursos vinculados a la longitud de la costa, bienes de interés cultural y espacios naturales protegidos con los movimientos turísticos en las comunidades autónomas españolas. Andalucía goza de una gran ventaja comparativa en la dotación de estos recursos territoriales, que la coloca potencialmente en una posición ventajosa para el desarrollo del cicloturismo, especialmente marcada en torno al recurso litoral y al patrimonio cultural. Esta fortaleza se torna en la categoría de ventaja competitiva, teniendo en cuenta los instrumentos de planificación en torno a la bicicleta y al turismo sostenible en Andalucía, y su implementación futura.

Se propone un modelo multidimensional para el desarrollo del cicloturismo, que contribuya a configurar una imagen y marca territorial difícilmente imitable, basada en el capital territorial, que mejore la conectividad de hábitats y especies. Comparando la situación actual de las dimensiones del modelo con el escenario deseado, es posible identificar puntos débiles o déficits, como la falta de infraestructuras ciclistas en determinadas zonas costeras, y por tanto, definir áreas potenciales de mejora.

\section{BIBLIOGRAFÍA}

Alliance for Biking \& Walking (2012): Bicycling and walking in the United States 2012. Benchmarking Report. Alliance for Biking \& Walking.

Andalbike (2014): "Estudio sobre las preferencias del cicloturista de monta-a". [En línea], <http://www.andalbike.com/> [10 de julio de 2014].

Adeac (2013): Playas con bandera azul. Adeac. [En línea], <http://www.adeac.es/sites/default/files/archivos/tabla\%20estadistica\%20PLAYAS\%2 0\%28Tabla\%202\%29.pdf > [25 de julio de 2014].

Brandenburg,C.; Matzarakis, A.; Arnberger, A. (2007): "Weather and cycling - a first approach to the effects of weather conditions on cycling". Meteorological Applications. 14: 61-67. http://dx.doi.org/10.1002/met.6

Bundesministerium für Wirtschaft und Technologie. (2009): Grundlagenuntersuchung Fahrradtourismus in Deutschland. Forschungsbericht Nr. 583. [En línea], $<$ www.bmwi.de $>$ [20 de julio de 2014].

Camagni, R. \& Capello, R. (2013): "Regional Competitiveness and Territorial Capital: A Conceptual Approach and Empirical Evidence from the European Union", Regional Studies, 47:9. http://dx.doi.org/10.1080/00343404.2012.681640

ISSN: 0212-8594 ISSN-e: 2340-2776.№ DOI: http://dx.doi.org/10.12795/rea.2015.i32.04 

cicloturismo.

Commission of the European Communities (2013): Com (2013) 249 final. Communication from the Commission to the European Parliament, the Council, the European Economic and Social Committee and the Committee of the Regions. Green infrastructure (gi) -enhancing Europe's natural capital. \{SWD(2013) 155 final\}. [En línea], <http://www.eea.europa.eu/publications/green-infrastructure-and-territorialcohesion> [10 de julio de 2014].

Commission of the European Communities (2006a): Com (2008) 616 final. Communication from the Commission to the Council, the European Parliament, the Committee of the Regions and the European Economic and Social Committee. Green paper on territorial cohesion. Turning territorial diversity into strength. Commission of the European Communities.

Commission of the European Communities. (2006b): A renewed EU Tourism Policy: Towards a stronger partnership for European Tourism. Commission of the European Communities. [En línea],

<http://europa.eu/legislation_summaries/enterprise/industry/n26107_en.htm> [10 de julio de 2014].

Cohen, S. A., Higham, J. E. S., Peeters, P., \& Gössling, S. (2014): "Why tourism mobility behaviours must change". In S. A. Cohen, J. E. S. Higham, P. Peeters \& S. Gössling (Eds.), Understanding and governing sustainable tourism mobility: Psychological and behavioural approaches (pp. 1-12). Routledge, Abingdon, UK.

Consejería de Comercio y Turismo (2013): Microproductos y Segmentos Emergentes. Consejería de Comercio y Turismo. [En línea],

< http://www.andalbike.com/contenidos/noticias/133-1.pdf > [10 de julio de 2014].

Consejería de Fomento y Vivienda. (2014): Plan Andaluz de la bicicleta. PAB 20142020. Consejería de Fomento y Vivienda. [En línea], <http://www.juntadeandalucia.es/fomentoyvivienda/portalweb/web/areas/transportes/plan_bici> [6 de julio de 2014].

Consejería de Medio Ambiente. (2001): Acuerdo de 27 de marzo de 2001, del Consejo de Gobierno, por el que se aprueba el Plan para la Recuperación y Ordenación de la Red de Vías Pecuarias de la Comunidad Autónoma de Andalucía. Consejería de Medio Ambiente.

Consejería de Medio Ambiente y Ordenación del Territorio (2014a): Ruta cicloturística Transnevada. [En línea],

<http://www.juntadeandalucia.es/medioambiente/corredorVerde/index.do > [30 de julio de 2014]. 
Consejería de Medio Ambiente y Ordenación del Territorio (2014b): Ruta cicloturística Transnevada. [En línea],

<http://www.juntadeandalucia.es/medioambiente/servtc5/ventana/mostrarFicha.do;jsessioni $\mathrm{d}=72$ CE1749290F046EC16449E9D2962393?idEquipamiento=43604> [30 de julio de 2014].

Consejería de Obras Públicas y Transportes. (2006): Plan de Ordenación del Territorio de Andalucía (POTA.) [En línea],

<http://www.juntadeandalucia.es/medioambiente/site/portalweb/menuitem.7e1cf46 ddf59bb227a9ebe205510e1ca/?vgnextoid=b59ff7ffa3828310VgnVCM1000001325e50 aRCRD\&vgnextchannel=7e7e8a3c73828310VgnVCM2000000624e50aRCRD> [10 de julio de 2014].

Consejería de Turismo y Comercio (2014a): Registro de empresas de turismo activo. Consejería de Turismo y Comercio. Junta de Andalucía.

Costa del Sol Golf Club (2014): Jugar al golf y montar en bici: todo en uno gracias a The Golf Bike. [En línea], <http://blog.golfcostadelsol.org/?p=469> [26 de agosto de 2014].

Cope, A., Downward, P., \& Lumsdon, L. (2004): "Monitoring long distance trails: The North Sea Cycle Route". Journal of Transport Geography, 12(1), 13-22.

http://dx.doi.org/10.1016/j.jtrangeo.2003.10.

Dematteis, G. y Governa, F. (2005): "Territorio y territorialidad en el desarrollo local. la contribución del modelo SLOT". Boletín de la A.G.E. N. 39, pp. 31-58. [En línea], $<$ http://www.boletinage.com/articulos/39/02-TERRITORIO.pdf> [10 de julio de 2014].

Dickinson, J.E. and Robbins, D. (2009): "Other People, Other Times and Special Places: a Social Representations Perspective of Cycling in a Tourism Destination", Tourism and Hospitality Planning and Development, 6(1), pp. 69-85.

http://dx.doi.org/10.1080/14790530902847095

European Commission (1999): ESDP -European Spatial Development Perspective. Towards Balanced and Sustainable Development of the Territory of the European Union. European Commission.

European Greenways Association. (2014): [En línea], $<\underline{w w w . a e v v-e g w a . o r g}>[10$ de junio de 2014].

Eijgelaar, E., Peeters, P. \& Piket, P. (2013): European cycle tourism: tool for sustainable regional rural development.

Eijgelaar, E., Piket, P.C. \& Peeters, P.M. (2011): "Have bicycle, will travel: cycle tourism is no longer a niche market". Cyclingmobility, 2011(1), 48-51.

ISSN: 0212-8594 ISSN-e: 2340-2776.№ DOI: http://dx.doi.org/10.12795/rea.2015.i32.04

REA 32 (2015):76-107

http://editorial.us.es/es/revista-de-estudios-andaluces 
EuroVelo - the European Cycle Route Network. (2014): [En línea], < http://www.eurovelo.org> [1 de julio de 2014].

Excelltur. (2013): UrbanTur 2012. Monitor de competitividad turística de los destinos urbanos españoles. Excelltur.

Fagerberg, J.; Verspagen, B. and Caniëls, M. (1997): "Technology, growth and unemployment across European regions", Regional Studies 31, 457-66.

http://dx.doi.org/10.1080/00343409750132252

Fernández-Latorre, F.M. (2012): Formación, investigación e innovación en turismo. Editorial Digital@tres. [En línea],

<http://dialnet.unirioja.es/servlet/libro?codigo=496941> [14 de agosto de 2014].

Fernández-Latorre, F. M. (2011a): “Dinámicas energéticas y turísticas. Relaciones y reacciones en Canarias". XXII Congreso de Geógrafos Españoles. [En línea], $<$ http://dialnet.unirioja.es/servlet/articulo?codigo=3804576> [16 de agosto de 2014].

Fernández-Latorre, F. M. y Díaz del Olmo, F. (2011b): “Huella Ecológica y presión turística socio-ambiental. Aplicación en Canarias". Boletín de la Asociación de Geógrafos Españoles № 57, pp. 147-173. [En línea], <http://www.boletinage.com/articulos/57/07-HUELLA.pdf> [15 de agosto de 2014].

Fernández-Latorre, F. M. and Díaz del Olmo, F. (2011c) Ecological Footprint and SocialEnvironmental Tourism Pressure. Application to the Canary Islands. Boletín de la Asociación de Geógrafos Españoles № 57. [En línea], <http://www.boletinage.com/articulos/57/23-HUELLA.pdf > [15 de junio de 2015].

Fernández-Latorre, F.M. (2006). Indicadores de sostenibilidad y medio ambiente; métodos y escala. Consejería de Medio Ambiente. [En línea], <http://www.juntadeandalucia.es/servicios/publicaciones/detalle/47455.html>[25 de agosto de 2014].

Fundación ECA Bureau Veritas- Dirección General de Tráfico. (2011): Barómetro anual de la bicicleta. España. Informe de resultados.

Fundación de Ferrocarriles Españoles. (2008): Creación del producto cicloturismo en Vías Verdes. Mercado, comunicación y desarrollo. Madrid [En línea], <http://www.viasverdes.com/prensa/documentos/interes/Estudio_Ciclotur.pdf > [1 de julio de 2014].

Fundación de Ferrocarriles Españoles y Consejería de Fomento y Vivienda (2014): Vías Verdes de Andalucía. Fundación de Ferrocarriles Españoles, Consejería de Fomento y

ISSN: 0212-8594 ISSN-e: 2340-2776.N№ DOI: http://dx.doi.org/10.12795/rea.2015.i32.04 
vivienda de la Junta de Andalucía, Unión Europea, Universidad de Sevilla. [En línea], $<$ http://www.viasverdes.com/vvandalucia/> [20 de agosto de 2014].

Fundación de Ferrocarriles Españoles. (2011): Desarrollo sostenible y empleo en las Vías Verdes. Programa empleaverde de la Fundacion Biodiversidad. Madrid. [En línea], $<$ http://www.viasverdes.com/ > [5 de julio de 2014].

Fundación Vía Verde de la Sierra. (2014): [En línea], $<$ www.fundacionviaverdedelasierra.com > [5 de julio de 2014].

Fundación RACC. (2010): Comparativa de bicicletas eléctricas. RACC-ADAC. [En línea], <http://www.econduccion.es/uploads/20100930/PEDELECS_test_2010.pdf> [10 de julio de 2014].

Frontur. (2014): [En línea], <http://www.iet.tourspain.es/eses/estadisticas/frontur/paginas/default.aspx > [20 de julio de 2014].

Giffinger, R., Suitner, J. (2010): “Danube Region Strategy - Arguments for a Territorial Capital Based Multilevel Approach". SPATIUM International Review UDC 711.2(4924.56). No. 23, October 2010, pp. 9-16. [En línea], <http://www.doiserbia.nb.rs/img/doi/1450-569X/2010/1450-569X1023009G.pdf> [22 de julio de 2014].

Holanda Natural (2014): Cruceros en Barco y Bici. [En línea], <http://www.holandanatural.com/creuers_en_vaixell_bicicleta_esp.php> [22 de julio de 2014].

IECA. (2014): Instituto de Estadística y Cartografía de Andalucía. [En línea], <http://www.juntadeandalucia.es/institutodeestadisticaycartografia/temas/tema02.ht $\mathrm{ml}>$ [3 de julio de 2014].

ITB (2013): World Travel Trends Report 2013/2014. ITB.

INE (2008). Encuesta de Hogares y Medio Ambiente 2008. INE.

Lamont, M. (2009): "Reinventing the Wheel: a Definitional Discussion of Bicycle Tourism", Journal of Sport and Tourism, 14(1), pp. 5-23.

http://dx.doi.org/10.1080/14775080902847363

LLumsdon, L. (2000): Transport and Tourism: Cycle Tourism - A Model for Sustainable Development?, Journal of Sustainable Tourism, 8:5, 361-377.

http://dx.doi.org/10.1080/09669580008667373

ISSN: 0212-8594 ISSN-e: 2340-2776.N№ DOI: http://dx.doi.org/10.12795/rea.2015.i32.04

REA 32 (2015):76-107

http://editorial.us.es/es/revista-de-estudios-andaluces 
Lumsdon, L. \& Peeters, P.M. (2009): "Transport and tourism: is there a sustainable future?" Tourism and Hospitality Planning \& Development, 6(1), 1-5.

http://dx.doi.org/10.1080/14790530902846998

Mato i Palos, E. y Troyano, X. (2014): El impacto económico del cicloturismo en Europa. Síntesis de los principales estudios realizados. 2014. Consejería de Fomento y Vivienda. Junta de Andalucía. [En línea],

$<$ http://www.viasverdes.com/prensa/documentos/interes/Informe_Cicloturismo_201 4.pdf $>$ [8 de agosto de 2014].

Meschik, M. (2012): "Sustainable Cycle Tourism along the Danube Cycle Route in Austria", Tourism Planning \& Development, 9:1, 41-56.

http://dx.doi.org/10.1080/21568316.2012.653478

MInisterio de Medio Ambiente. (2014): [En línea], <http://www.magrama.gob.es/es/desarrollo-rural/temas/politica-forestal/viaspecuarias/rvp_recuperacion.aspx> [16 de agosto de 2014].

Mundet, LL. \& Coenders, G. (2010): "Greenways: a sustainable leisure experience concept for both communities and tourists". Journal of Sustainable Tourism. 18:5,657674. http://dx.doi.org/10.1080/09669581003668524

Navigant Research. (2013): "Executive Summary: Electric Bicycles Global Market Opportunities, Barriers, Technology Issues, and Demand Forecasts for E-Bicycles, PedalAssist Bicycles, and E-Bicycle Batteries and Motors". Navigant Research.

Ortega, G. (2014): “El cicloturismo en la planificación turística de Andalucía”. I Jornada divulgativa sobre vías verdes de Andalucía: el impacto del cicloturismo y las vías verdes. Consejería de Turismo y Comercio. [En línea], <http://www.viasverdes.com/vvandalucia/pdf/Jornada01/GERMANORTEGA.pdf> [23 de agosto de 2014].

OTREMED.(2012): Tools of territorial strategy of the Med space. Final report /Territorial factors. OTROMED. [En línea],

<http://sdimed.imida.es/downloads/Otremed_Territorial_Factors.pdf $>[26$ de agosto de 2014].

Palau, R., Forgas, S., Blasco, D. \& Ferrer, B. (2012): “An Analysis of Greenways from an Economic Perspective". Tourism Planning \& Development. Volume 9, Issue 1, Special Issue: low carbon tourism travel: cycling, walking and trails.

Peeters, P.M., Szimba, E. \& Duijisveld, M. (2007): "Major environmental impacts of European tourist transport". Journal of Transport Geography, 15(2), 83-93. http://dx.doi.org/10.1016/j.jtrangeo.2006.12.007

ISSN: 0212-8594 ISSN-e: 2340-2776.N№ DOI: http://dx.doi.org/10.12795/rea.2015.i32.04 
Peeters, P. \& Schouten, F. (2006): "Reducing the Ecological Footprint of Inbound Tourism and Transport to Amsterdam", Journal of Sustainable Tourism, 14:2, 157-171. http://dx.doi.org/10.1080/09669580508669050

Pompili, T., Martinoia,M. (2011): "Building synthetic indicators for aspects of territorial capital". European Regional Science Association. $51^{\text {st }}$ European Congress. Barcelona.

Pucher, J., Buehler, R., \& Seinen, M. (2011): "Bicycling renaissance in North America? An update and re-appraisal of cycling trends and policies". Transportation Research Part A: Policy and Practice, 45(6), 451-475. doi:10.1016/j.tra.2011.03.001.

http://dx.doi.org/10.1016/j.tra.2011.03.001

Pucher, J.; Dill,J., Handy, S (2010): "Infrastructure, programs, and policies to increase bicycling: An international review", Preventive Medicine, Volume 50, Supplement, January, pp. 106-125. http://dx.doi.org/10.1016/j.ypmed.2009.07.028

Pucher, J., Buehler, R., 2007: "At the frontiers of cycling: policy innovations in the Netherlands, Denmark, and Germany". World Transport Policy and Practice 13 (3), 857.

Red de ciudades por la bicicleta. (2014): [En línea], < http://www.ciudadesporlabicicleta.org/ > [3 de septiembre de 2014].

Red de Ciudades por la Bicilcleta, (2011). Llamamiento a la cooperación de comunidades ciclables en el mundo. [En línea], $<$ http://svqenbici.files.wordpress.com/2012/03/declaracion-de-sevilla-red-deciudades-por-la-bicicleta.pdf> [1 de septiembre de 2014].

REDIAM (2014). Red de Información Ambiental de Andalucía. [http://www.juntadeandalucia.es/medioambiente/site/rediam/menuitem.aedc2250f6 db83cf8ca78ca731525ea0/?vgnextoid=373203d78270f210VgnVCM2000000624e50aR CRD\&Ir=lang_es> En línea [2 de septiembre de 2014].

Ritchie, W. B. (1998): "Bicycle tourism in the South Island of New Zealand: planning and management issues". Tourism Management, Vol. 19, № 6,pp.567-582.

http://dx.doi.org/10.1016/S0261-5177(98)00063-6

Simonsen, P and Jorgenson, B. (1996): Cycling tourism: environmental and economical sustainability?. Unpublished Report, Bornholm Research Centre, Denmark.

Simpson, M. C., Gossling, S., Scott, D., Hall, C. M., \& Gladin, E. (2008): Climate change adaptation and mitigation in the tourism sector: frameworks, tools and practices. United Nations Environment Programme. Oxford. 
Storper, M. (1997): "Le economie locali come beni relazionali", Sviluppo locale, IV, 5, pp. 5-42.

Sustrans. (1999): "Cycle tourism" (Vol. Information pack TT 21). Sustrans, Bristol, UK. Trasmediterranea (2014): Planes con bici. [En línea], <http://w3.trasmediterranea.es/es/guia-del-pasajero/default/planes-bici/> $\left[\begin{array}{ll}5 & \text { de }\end{array}\right.$ septiembre de 2014].

TrasAndalus.(2014): TrasAndalus. [En línea], < http://www.transandalus.org/> [3 de septiembre de 2014].

The City of Copenhagen. (2014): Good, Better, Best. The City of Copenhagen's Bicycle Strategy 2011-2025.The City of Copenhagen. Technical and Environmental Administration Traffic Department. [En línea], <www.kk.dk/cityofcyclists > [12 de agosto de 2014].

The Gallup Organization. (2011): Flash Eurobarometer 312 "Future of transport". European Commission. Brussels. [En línea], $<>$ [3 de julio de 2014].

Trendscope. (2010): Radreisen der Deutschen 2010. Trendscope GbR. Cologne, Germany. [En línea], <> [13 de julio de 2014].

VisitMallorca (2014): Cicloturismo en Mallorca. [En línea], <http://www.visitmallorca.com/activate/deporte/cicloturismo-en-mallorca/28> [13 de julio de 2014].

Wang, G., Macera, C., Scudder-Soucie, B., Schmid, T., Pratt, M., Buchner, D. (2005): "A cost-benefit analysis of physical activity using bike/pedestrian trails". Health Promotion Practice, April 2005, Volume 6, Number 2, pp. 174-179.

http://dx.doi.org/10.1177/1524839903260687

Weston, R., Davies, N., Lumsdon, L., McGrath, P., Peeters, P., Eijgelaar, E., \& Piket, P. (2012): The European Cycle Route Network EuroVelo. European Union. [En línea], <http://www.europarl.europa.eu/studies> [10 de agosto de 2014].

Weston, R., Mota, J. C. (2012): "Low Carbon Tourism Travel: Cycling, Walking and Trails", Tourism Planning \& Development, 9:1, 1-3.

http://dx.doi.org/10.1080/21568316.2012.658168

Zia Wadud (2014): "Cycling in a changed climate", Journal of Transport Geography, Vol. 35, pp. 12-20. http://dx.doi.org/10.1016/j.jtrangeo.2014.01.001

Zovko, I., (2013): The Value of Cycle Tourism. Opportunities for the Scottish economy. Tranform Scotland. [En línea], <www.scottishviewpoint.com> [12 de agosto de 2014].

ISSN: 0212-8594 ISSN-e: 2340-2776.№ DOI: http://dx.doi.org/10.12795/rea.2015.i32.04 